\title{
Highly Versatile Cell-Penetrating Peptide Loaded Scaffold For Efficient and Localized Gene Delivery To Multiple Cell Types: From Development to Application in Tissue Engineering
}

Rosanne M. Raftery ${ }^{1-3}$, David P. Walsh ${ }^{1-4}$, Lia Blokpoel Ferreras ${ }^{1-3}$, Irene Mencía Castaño ${ }^{1-3}$, Gang Chen ${ }^{5}$, Mark LeMoine ${ }^{1-3}$, Gizem Osman ${ }^{6}$, Kevin M. Shakesheff ${ }^{6}$, James E. Dixon ${ }^{6}$ and Fergal J. O'Brien ${ }^{1-3 *}$

\section{*Corresponding author}

F. J. O'Brien, Tissue Engineering Research Group, Department of Anatomy, Royal College of Surgeons in Ireland, 123 St. Stephen's Green, Dublin 2, Ireland.

Tel: +353(0)1 4022149

Fax: +353 (0)1 4022355

Email: fjobrien@rcsi.ie

\author{
Affiliations \\ ${ }^{1}$ Tissue Engineering Research Group, Dept. of Anatomy, Royal College of Surgeons in \\ Ireland, Dublin, Ireland \\ ${ }^{2}$ Trinity Centre for Bioengineering, Trinity College Dublin, Dublin, Ireland \\ ${ }^{3}$ Advanced Materials and Bioengineering Research Centre (AMBER), RCSI and TCD, \\ Dublin, Ireland \\ ${ }^{4}$ Translational Research in Nanomedical Devices, School of Pharmacy, Royal College of \\ Surgeons in Ireland, Dublin, Ireland \\ ${ }^{5}$ Department of Physiology and Medical Physics, Centre for the Study of Neurological \\ Disorders, Microsurgical research and training facility (MRTF), Royal College of \\ Surgeons in Ireland, Dublin, Ireland \\ ${ }^{6}$ Centre for Biomedical Sciences, School of Pharmacy, University of Nottingham, \\ Nottingham, United Kingdom
}

Keywords: GET, gene delivery, cell-penetrating peptide, tissue engineering, bone regeneration 


\begin{abstract}
Gene therapy has recently come of age with seven viral vector-based therapies gaining regulatory approval in recent years. In tissue engineering, non-viral vectors are preferred over viral vectors, however, lower transfection efficiencies and difficulties with delivery remain major limitations hampering clinical translation. This study describes the development of a novel multi-domain cell-penetrating peptide, GET, designed to enhance cell interaction and intracellular translocation of nucleic acids; combined with a series of porous collagen-based scaffolds with proven regenerative potential for different indications. GET was capable of transfecting cell types from all three germ layers, including stem cells, with an efficiency comparable to Lipofectamine ${ }^{\circledR}$ 3000, without inducing cytotoxicity. When implanted in vivo, GET gene-activated scaffolds allowed for host cell infiltration, transfection localized to the implantation site and sustained, but transient, changes in gene expression - demonstrating both the efficacy and safety of the approach. Finally, GET carrying osteogenic (pBMP-2) and angiogenic (pVEGF) genes were incorporated into collagen-hydroxyapatite scaffolds and with a single $2 \mu \mathrm{g}$ dose of therapeutic pDNA, induced complete repair of critical-sized bone defects within 4 weeks. GET represents an exciting development in gene therapy and by combining it with a scaffold-based delivery system offers tissue engineering solutions for a myriad of regenerative indications.
\end{abstract}

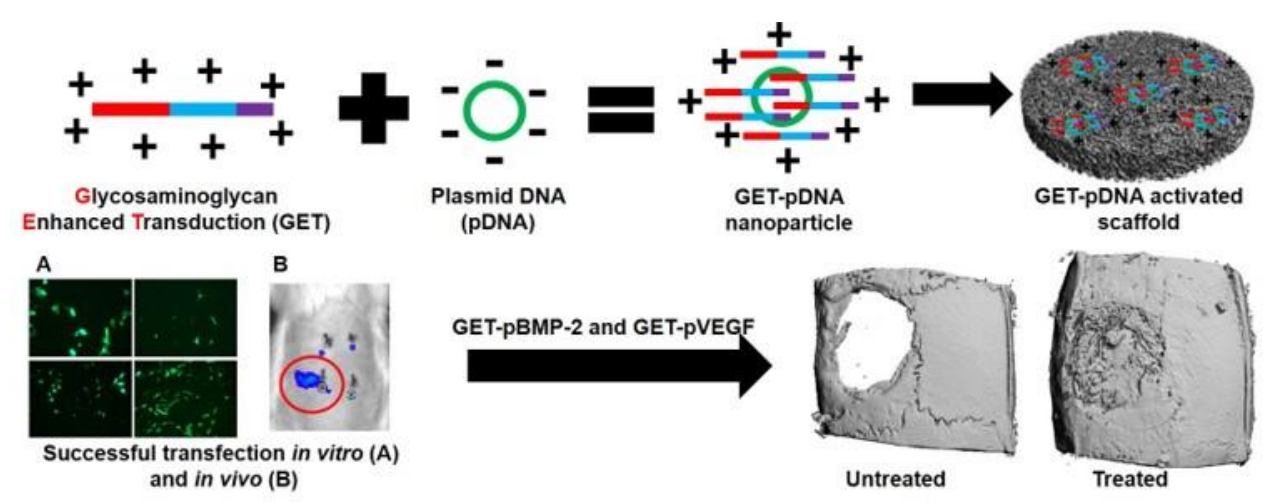




\section{Introduction}

Advances in our understanding of genetics, along with the development of new genetic sequencing and editing tools, means that personalized precision medicine is now within our grasp. Classical gene therapy is a type of precision medicine that can correct or restore a specific misspelled nucleic acid sequence by introducing the corrected version. Newer approaches include interfering with transcription, pre-mRNA splicing, mRNA catabolism or translation, resulting in over-expression or silencing of target genes, collectively opening up the entire genome to therapeutic intervention. [1] However, nucleic acid-based molecules have high molecular weights, are highly negatively charged, and are degraded rapidly in physiological conditions making intracellular delivery a major challenge. [2] Viral-based delivery vectors have had millions of years of evolutionary optimization making them extremely efficient in intracellular transfer of nucleic acids and, following years of enormous promise and equally colossal set-backs, seven viral-based gene therapy products have achieved regulatory approval in the past 6 years, including three in 2017 alone. [3-5] Having potentially overcome safety concerns with viral gene delivery, other limitations include limited nucleic acid loading capacity, immunogenicity and expense. Non-viral delivery vectors based on lipids, polymers and polysaccharides have been developed to circumvent limitations associated with viral vectors but the transfection efficiency is typically much lower, therefore, necessitating high doses to exert a response which can subsequently lead to off-target effects. Thus, there still exists a significant need for safe and efficient non-viral methods for intracellular gene delivery.

Cell-penetrating peptides (CPPs) are a group of structurally and physico-chemically diverse peptides but which share two common characteristics; they all contain fewer than 30 amino acids and they possess a natural ability to traverse the cell membrane. [6-8] This ability is not lost when the peptide is bound to a cargo such as proteins, drugs, antibodies, plasmid (p)DNA or siRNA and, when combined with their low immunogenicity and cytotoxicity, they represent a very promising option for gene therapy. It has been 30 years since two separate laboratories independently discovered 
that the transactivator of transcription (TAT) protein of HIV-1 could cross the cell membrane; $[9,10]$ work which led to the discovery that an 11 amino acid sequence of the TAT protein, simply called the TAT peptide, was responsible. [11] Six years later, Derossi and colleagues showed that the 16 amino acid third helix of the Drosophila Antennapedia homeoprotein, later called penetratin, shared the same property. [12] Common to both peptides was the high number of positively charged arginine in each sequence initiating research into synthetic arginine rich peptide sequences as intracellular delivery vectors. $[13,14]$ Polyarginine, in particular octaarginine (8R) and nonaarginine (9R) are examples of synthetic CPPs. [15-18] While the exact mechanism of how CPPs gain entry into cells remains unclear - they have been shown to work via active and passive mechanisms -the presence of positively charged amino acids are a key factor as well as high extracellular concentrations $(2-5 \mu \mathrm{M})$, therefore a high dose is typically required to ensure efficient intracellular translocation. [19]

To improve intracellular translocation while also lowering the dose required, Dixon and colleagues recently developed a multidomain peptide comprised of a glycosaminoglycan (GAG)-binding peptide sequence (P21) to stimulate cell membrane interaction, fused with an octaarginine (8R), a CPP capable of crossing the cell membrane. [20] As this peptide relies on GAG-binding to enhance intracellular delivery efficiency, the concept has been termed GAG-binding enhanced transduction (GET). GET is capable of highly efficient delivery of a plethora of functional cargos including proteins, antibodies and nucleic acids, to a number of different cell types for different applications and most importantly, at low doses. [21, 22] Another version of GET, consisting of a 16-residue heparan sulfate-GAG binding peptide derived from the fibroblast growth factor 2 (FGF2) protein (FGF2B domain); LK15, an amphiphilic pan-nucleic acid interaction sequence; and $8 \mathrm{R}$, together called (FLR) was also developed and showed promise in preliminary in vitro studies. However, when applied for in vivo delivery to the lung, the GET peptide needed to be PEGylated to enhance stability, which reduced transfection efficiency. [23]

In the development of an efficient system of gene delivery for use in vivo, five key criteria need to be considered; 1) ability to efficiently transfect many cells including socalled 'difficult too transfect' cells such as stem cells; 2) low cytotoxicity; 3) localized delivery at the target site; 4) therapeutic activity at low doses and 5) evidence of 
therapeutic application. In vivo gene delivery involves the administration of genes either systemically or locally. If a gene delivery vector is administered systemically, retention time and clearance must be considered due to the short half-life of pDNA in the presence of endonucleases. Local administration can reduce these effects and improve retention at the site required however, depending on the target tissue, can sometimes cause damage to the surrounding tissues such as retinal detachment following sub-retinal injection.[24] Hydrocarbon chains have been added to proline-rich CPPs to increase their circulation times, [25] while RGD moieties have been added to target specific tissues. [26] Osman and colleagues showed that by PEGylating GET-pDNA nanoparticles before delivery to mouse lungs, the nanoparticles maintained colloidal stability in physiological fluids and induced significantly higher transgene expression when compared to unmodified GETpDNA nanoparticles. [23] Another method to control distribution and provide nanoparticle protection, and one that is particularly useful in tissue engineering and regenerative medicine is to incorporate the nanoparticles into a biomaterial scaffold, termed a gene-activated scaffold or matrix. The scaffold then effectively acts as the gene delivery device upon implantation allowing for the controlled release of the gene to cells as they infiltrate through the three-dimensional matrix. Simultaneously, the scaffold provides mechanical support during regeneration and can be custom designed to mimic the native extracellular matrix of the tissue it is replacing. This method was first used by Fang and colleagues in 1996 [27] and since then many more iterations have been developed for different tissue engineering applications including in our laboratory where pDNA, siRNA and miRNAs complexed with polyethyleneimine (PEI), nanohydroxyapatite (nHA), chitosan or dendrimers have been delivered on collagenbased scaffolds for a number of different therapeutic indications. [28-37]

The aim of this study was to develop and optimize a scaffold-based system for the localized delivery of the GET peptide allowing for safe, efficient therapeutic gene delivery. Specifically, the first aim was to determine the optimal GET-pDNA nanoparticle formulation involving physicochemical characterization, in vitro efficacy and biocompatibility testing, and in vivo safety and efficacy testing. The second aim was to demonstrate the versatility of GET peptide by delivering genes to a number of different cell types representing cells from endoderm, mesoderm and ectoderm. Finally, to 
demonstrate the translational potential of GET-pDNA-activated scaffolds, bone regeneration was chosen as a specific therapeutic target and GET-pDNA activated scaffolds were developed, optimized and tested in vitro before being applied in the repair of critical-sized bone defects in vivo. 


\section{Materials and Methods}

Sigma Aldrich, Ireland, supplied all materials unless otherwise stated.

\subsection{GET-pDNA nanoparticle characterisation}

2.1.1 Peptide synthesis: Peptides were synthesised using solid phase t-Boc chemistry and purified to $>90 \%$ by Protein Peptide Research Ltd (PPR, UK).

2.1.2 Plasmid propagation: Plasmids encoding the reporter genes Gaussia Luciferase (pGLuc; New England Biolabs, Massachusetts, USA) and green fluorescent protein (pZsGreen1; TakaraBio), and therapeutic genes bone morphogenetic protein (pBMP-2; kindly donated by Prof. Kazihusa Bessho, Kyoto University, Japan) and, vascular endothelial growth factor (pVEGF; purchased from Genecopaeia (USA)), all under the control of the cytomegalovirus promoter were propagated by transforming One Shot ${ }^{\circledR}$ TOP10 Chemically Competent E. coli bacterial cells according to the manufacturer's protocol. pDNA was purified and collected using the Endotoxin free Maxi-prep kit (Qiagen, UK).

2.1.3 GET-pDNA complex formulation: GET-pDNA complexes were formulated at three charge ratios of GET to pDNA (CR 3:1, 4:1 and 5:1, simply referred to as CR 3, 4 and 5 respectively) with the pDNA dose remaining constant at $2 \mu \mathrm{g}$. GET was added to pDNA and allowed to complex for 15 minutes via electrostatic interaction between the LK15 component of the GET peptide and the pDNA.

2.1.4 GET-pDNA complex characterisation: Dynamic light scattering (DLS) was used to measure nanoparticle size and polydispersity and electrophoretic light scattering (ELS) was used to measure complex zeta potential (Zetasizer 3000 HS, Malvern, UK). GETpDNA nanoparticles were made as described in Section 2.1.3 and the volume was brought up to $1 \mathrm{~mL}$ using molecular grade water and transferred to a zeta-cell (Malvern, UK) for analysis. Measurements were triplicated for three batches of nanoparticles and results are the average of three measurements. A SYBR ${ }^{\mathrm{TM}}$ Safe (Biosciences Ireland) exclusion assay was used to quantify complexation efficiency. Briefly, GET-pDNA nanoparticles were prepared as in Section 2.1.3 and then diluted to $1.5 \mathrm{~mL}$ with molecular 
grade $20 \mathrm{mM} \mathrm{NaCl}$. SYBR ${ }^{\mathrm{TM}}$ Safe DNA stain was then added and the fluorescence signal read, in triplicate, on a spectrofluorimeter (Perkin Elmer LS 50B) at an excitation wavelength of $488 \mathrm{~nm}$ and an emission wavelength of $522 \mathrm{~nm}$. To visualise the stability of GET-pDNA complexes when exposed to "physiological conditions", GET-pDNA nanoparticles were formulated as described in Section 2.1.3 before $\mathrm{MgSO}_{4}$ was added to give a final concentration of $0.1 \mu \mathrm{M}$ and the samples were either incubated at $37^{\circ} \mathrm{C}$ for $4 \mathrm{~h}$ with 8 units of DNase I per $1 \mu \mathrm{g}$ of DNA, or incubated in media containing $10 \%$ fetal bovine serum (FBS) for $12 \mathrm{~h}$. Each sample was subsequently run on a $1 \%$ agarose gel for 1 hour, along with controls as follows; 1 - Ladder; 2 - pDNA alone; 3 -pDNA alone in serum; 4 - pDNA alone in DNase; 5 - GET-pDNA at CR3; 6 - GET-pDNA at CR3 in serum; 7 - GET-pDNA at CR3 in DNase; 8 - GET-pDNA at CR4; 9 - GET-pDNA at CR4 in serum; 10 - GET-pDNA at CR4 in DNase; 11 - GET-pDNA at CR5; 12 - GETpDNA at CR5 in serum; 13 - GET-pDNA at CR5 in DNase. The gels were viewed and imaged using Amersham Imager 680 blot and gel imager (GE Healthcare).

\subsection{Assessment of GET-pDNA transfection efficiency in 2D monolayer, within 3D collagen-based scaffolds and when implanted in vivo}

2.2.1 Cell culture: Certified mesenchymal stem cells isolated from bone marrow of Sprague Dawley rats were purchased from Cyagen (USA) and cultured in growth media containing high glucose (4.5 g/L) Dulbecco's Modified Eagles Medium (DMEM) supplemented with $2 \%$ penicillin/streptomycin, 10\% FBS (Labtech, UK), $1 \%$ glutamax, and $1 \%$ non-essential amino acids. Cells were passaged at $70-90 \%$ confluency and expanded to passage 5 for all experiments. Human bone marrows were purchased from Lonza (Switzerland) and mesenchymal stem cells were isolated using standard protocols and stringent analysis of cell phenotype (tri-lineage differentiation and a full panel of cell surface markers), as described previously. [38] hMSCs were cultured in low glucose (1 g/L) Dulbecco's Modified Eagle Medium (DMEM), supplemented with $10 \%$ foetal bovine serum (FBS) and 1\% penicillin/streptomycin. Cells were passaged upon reaching 80-90\% confluency and used in experiments at passage 5. MC3T3 cells were cultured in alpha MEM and supplemented with 10\% FBS, 1\% penicillin/streptomycin and 1\% Glutamax (Gibco, Ireland) and used at passage 12. Human articular chondrocytes were 
purchased from Lonza (Switzerland) and were cultured in serum-free chondrocyte growth media to passage 4 before being used in experiments. $\mathrm{C} 2 \mathrm{C} 12$ cells, a mouse musculoskeletal progenitor line, were expanded in high glucose DMEM supplemented with $10 \%$ FBS, $2 \%$ penicillin/streptomycin, $1 \%$ Glutamax and $1 \%$ non-essential amino acids and used in experiments at passage 6. Human dermal fibroblasts were purchased from ATCC (USA) and cultured in low glucose DMEM supplemented with 10\% FBS and $1 \%$ penicillin/streptomycin and used in experiments at passage 5. Human Umbilical Vein Endothelial Cells (HUVECs) were purchased from Lonza (Switzerland) and expanded in EGM-2 BulletKit (also Lonza). HUVECs were used in experiments at passage 5. The Claycomb lab provided the HL-1 cardiac cell line and cells were cultured using previously published protocols and materials. [39] Ne4C cells (ATCC, USA), a mouse neuroectodermal cell line was cultured in alpha MEM supplemented with 10\% FBS, $1 \%$ penicillin/streptomycin and $1 \%$ Glutamax.

2.2.2 Transfection of cells with GET-pDNA: Cells were seeded in monolayer at a density of $0.5 \times 10^{6}$ cells per well on tissue culture-treated plastic $24 \mathrm{~h}$ prior to transfection. GET-pDNA nanoparticles were formulated as described in Section 2.1.3 at CR 3, 4 and 5, all carrying $2 \mu \mathrm{g}$ of pDNA. Cell growth media was changed immediately before transfection and GET-pDNA was added directly to the media at a volume of 50 $\mu \mathrm{L}$ per well. Lipofectamine ${ }^{\circledR} 3000$ (Invitrogen) was used as a control to represent commercially available vectors and was used as per manufacturers recommendations and a $2 \mu \mathrm{g}$ pDNA dose.

2.2.3 Gene-Activated Scaffold Fabrication: Four different collagen-based scaffolds collagen alone, collagen-glycosaminoglycan (chondroitin-6-sulfate) (Coll-GAG), [40] collagen hyaluronic acid (CHyA) [41] and collagen-hydroxyapatite (CHA) [42] were fabricated using a lyophilisation technique developed by O'Brien et al. [43] The scaffolds were cross-linked dehydrothermally (DHT) at $105{ }^{\circ} \mathrm{C}$ for $24 \mathrm{~h}$ at $0.05 \mathrm{bar}$ in a vacuum oven (Vacucell 22; MMM, Germany), [44] followed by chemical cross-linking using a mixture of $6 \mathrm{mM} \mathrm{N}$-(3-Dimethylaminopropyl)-N'-ethylcarbodiimide hydrochloride (EDC) and $5.5 \mathrm{mM} \mathrm{N}$-Hydroxysuccinimide (NHS). GET-pDNA complexes were soakloaded onto each scaffold to make gene-activated scaffolds. A $8 \mathrm{~mm}$ biopsy punch was 
used to cut the scaffold to size and scaffolds were hydrated in PBS prior to use. GETpDNA complexes at each CR and carrying $2 \mu \mathrm{g}$ of pDNA (Section 2.1.3) were soakloaded onto each scaffold to make gene-activated scaffolds. In non-adherent tissue culture plates, $0.5 \times 10^{6}$ cells were seeded onto each scaffold and following a 30 minute incubation, the wells were flooded with media and incubated at $37^{\circ} \mathrm{C}$ with $5 \% \mathrm{CO}_{2}$.

2.2.4 Assessment of transfection efficiency using reporter plasmids: GET-pGFP nanoparticles were formulated as described in Section 2.1.3 at CR 3, 4 and 5 all carrying $2 \mu \mathrm{g}$ of pGFP. Following transfection as described in Section 2.2.2, fluorescent microscopy was used to visualise cells expressing GFP using a Leica DMIL microscope (Leica Microsystems, Switzerland). The cells were then fixed in 5\% formalin and GFP+ cells were quantified using FACS Canto 11 with FlowJo software.

Due to difficulties with removing cells from the gene-activated scaffolds (Section 2.2.3) to quantify GFP+ cells, scaffolds were instead loaded with GET-pGLuc. Gaussia Luciferase is a luminescent protein that is secreted into the medium. Therefore, following transfection with GET-pGLuc, samples of media were removed at each time-point and luciferase content was assessed using a Pierce ${ }^{\mathrm{TM}}$ Gaussia Luciferase Flash Assay kit (Thermo Scientific, Ireland) as per manufacturer's instructions.

2.2.5 Measurement of cell viability post-transfection: Metabolic activity was determined using a MTT Cell Growth assay (Millipore ${ }^{\mathrm{TM}}$, Ireland) performed at day 3 post-transfection as described previously. [30] Briefly, $10 \mu \mathrm{L}$ of MTT reagent was added to the cells in $90 \mu \mathrm{L}$ of media and incubated for $4 \mathrm{~h}$ at $37^{\circ} \mathrm{C}$. The supernatant was removed and $50 \mu \mathrm{L}$ of dimethyl sulfoxide (DMSO) was added to dissolve the formazan crystals, formed by metabolically active cells, leaving behind a purple colour. The intensity of the resulting colour was read at an absorbance of $570 \mathrm{~nm}$ using a reference wavelength of $630 \mathrm{~nm}$ using a Varioskan Flash multimode plate reader (Fisher Scientific, Ireland). Colour intensity emitted by untransfected cells was set at $100 \%$ and the GETtreated groups were calculated in relation to the untransfected control. A PicoGreen dsDNA kit (Invitrogen, Biosciences, Ireland) was used according to the manufacturer's instructions to estimate DNA concentration and therefore cell proliferation at days 1, 3, 7 and 14 post-transfection. Cells or scaffolds was placed in sodium carbonate buffer 
containing $0.1 \%$ Triton X-100 to lyse cells. DNA concentration was deduced using a standard curve.

\subsubsection{Assessment of transfection efficiency of gene-activated scaffolds following} subcutaneous implantation in vivo: Envigo, UK supplied adult male Wistar rats. The subcutaneous implant experiments were conducted in accordance with protocols approved by the Research Ethics Committee of the Royal College of Surgeons in Ireland (REC 1354) and by the Health Products Regulatory Authority (Project authorization No. AE19127/P037) in compliance with EU directive 2010/EU/63. Four longitudinal skin incisions $(1 \mathrm{~cm})$ were made bi-laterally ( 2 per side; a total of 4 per animal) along the rat spine, with a minimum gap space of $1 \mathrm{~cm}$ between incisions. The subcutaneous space was opened to create a pocket and the scaffold was placed inside before the skin was sutured using 4.0 Vicryl absorbable sutures $(n=3)$. At 3, 7, and 14 days post-implantation, the animals were anesthetized using inhalational isoflurane before coelenterazine was injected subcutaneously. After 5 minutes bioluminescence was imaged using an in vivo imaging system (IVIS: Perkin Elmer, UK) for 1 minute using optimized optics and resolution settings. The intensity of bioluminescence by endogenous cells was measured using Perkin Elmer Living Image software. The signal intensity is represented by radiance $\left(\mathrm{p} / \mathrm{sec} / \mathrm{cm}^{2} / \mathrm{sr}\right)$, which refers to the number of photons per second that are leaving a square centimeter of tissue and radiating into a solid angle of one steradian (sr).

\subsection{Investigating the therapeutic efficacy of GET-pDNA-activated scaffolds using bone regeneration as a case study}

For in vitro studies, rMSCs were cultured as described in Section 2.2.1. The therapeutic plasmids chosen - pBMP-2 and pVEGF, were propagated as described in Section 2.1.2. GET-pBMP-2 (CR4; $2 \mu \mathrm{g}$ of pBMP2), GET-pVEGF (CR4; $2 \mu \mathrm{g}$ of pVEGF) or GETpDual (CR4; $1 \mu \mathrm{g}$ of pBMP-2 and $1 \mu \mathrm{g}$ of pVEGF) were prepared as described in Section 2.1.3. Collagen hydroxyapatite scaffolds [42] were used in this part of the study and prepared as described in Section 2.2.3.

\subsubsection{Enzyme-Linked Immunosorbent Assay (ELISA) for BMP2 and VEGF} Quantification Post-Transfection: ELISAs (R\&D Systems, UK) were used to quantify the levels of BMP-2 and VEGF protein expressed by cells transfected with each gene as 
well as the combination of both genes (pDual). The cell culture supernatant was collected and analysed at days 3, 7, 10 and 14. Assays were carried out according to the manufacturer's instructions and the absorbance of each sample was read at $450 \mathrm{~nm}$ using a Varioskan Flash multimode plate reader (Fisher Scientific, Ireland) and the quantity of BMP-2 and/or VEGF protein present was deduced by calculating against a standard curve.

2.3.2 MSC Osteogenesis differentiation assay: Cells were cultured in 2D monolayer or on scaffolds in growth media (GM control), or osteogenic media (OM) consisting of DMEM supplemented with $10 \%$ FBS, $1 \%$ penicillin/streptomycin, $10 \mathrm{mM} \quad \beta$ glycerophosphate, $50 \mu \mathrm{M}$ ascorbic acid-2-phosphate and 100nM dexamethasone. In 2D culture, alkaline phosphatase activity was quantified at day 7 post-transfection using a SensoLyte ${ }^{\circledR}$ pNPP Alkaline Phosphatase assay kit (Cambridge Biosciences, Ireland). Calcium deposition was assessed at day 14 post-transfection using a Stanbio calcium CPC Liquicolour assay (Stanbio Inc., USA). In 3D gene-activated scaffold studies, calcium deposition was assessed by staining $7 \mu \mathrm{m}$ sections of paraffin embedded samples using alizarin red as described previously $[32,33]$ and calcium content was quantified as in $2 \mathrm{D}$ experiments.

2.3.3 In vivo calvarial defect repair: Envigo, UK supplied adult male Wistar rats for in vivo experiments. The calvarial critical-sized defect model experiments were conducted in accordance with protocols approved by the Research Ethics Committee of the Royal College of Surgeons in Ireland (REC 1350) and by the Health Products Regulatory Authority (HPRA) (Project authorization No. AE19127/P036) in compliance with EU directive 2010/EU/63. The surgical procedure has been described previously. [32, 33] Four weeks post-implantation, samples were harvested and analysis of new bone formation was performed using microCT and histomorphometry as described previously $(n=8)$. [32] New blood vessel formation was quantified by staining endothelial cells using CD31 antibody as described previously $(n=8)$. [32]

2.4 Statistical analysis: Results are expressed as mean \pm standard deviation unless stated otherwise. Statistics were carried out using Graphpad Prism software using a general linear model ANOVA with Bonferroni or Tukey post-hoc analysis performed for 
multiple comparisons. $\mathrm{p} \leq 0.05$ values were considered statistically significant where * $\mathrm{p}<0.05, * * \mathrm{p}<0.01$ and $* * * \mathrm{p}<0.001$.

\section{Results and Discussion}

The purpose of using GET was to facilitate intracellular translocation of a therapeutic cargo, in this case, plasmid DNA (pDNA). The first aim of this study was therefore to characterize GET-pDNA complexes at different formulations to assess suitability for transfection. When complexed with pDNA at charge ratios of 3, 4 and 5, the diameter of the GET-pDNA nanoparticles progressively increased from $119 \pm 7.1 \mathrm{~nm}$ (CR3) to $167 \pm$ $5.5 \mathrm{~nm}$ (CR5) as determined using dynamic light scattering (Figure 1A). The zeta potential also increased minimally with increasing CR from $26.2 \pm 0.1 \mathrm{mV}$ at CR3 to 30 $\pm 0.3 \mathrm{mV}$ at CR5 (Figure 1B). Size and zeta potential are normally crucial factors in determining the transfection efficiency of a non-viral gene delivery vector, [45-47] however, as GET contains a cell-penetrating peptide sequence, size becomes less important. Nevertheless, nanoparticles within the size-range reported in this study will serve only to enhance the transfection efficiency of GET-pDNA nanoparticles.

What remains a critical point with cell-penetrating peptides is the complexation efficiency of pDNA to the GET peptide. Arginine-rich CPPs can be conjugated to pDNA by covalent or non-covalent methods; covalent conjugation is most often used because the disulfide bridge formed between the CPP and cargo is easily cleaved in the reductive environment of the endosome, releasing the cargo. [48] However, this method is unsuitable for the delivery of large nucleic acids like pDNA. Non-covalent conjugation is used less often and relies on electrostatic charge interaction between the CPP and pDNA, which can be inefficient. The inclusion of LK15 in the FLR GET peptide used in this study enhances the condensation of pDNA into nanoparticles, protecting the pDNA from degradation. It has previously been reported that the binding efficiency of GET to pDNA is over 90\%, [23] and this was also observed in this study with complexation efficiency increasing with $\mathrm{CR}$ from $82 \pm 4.6 \%$ at CR3, $91 \pm 3.4 \%$ at CR4 to $94.5 \pm 1$ at CR5 as measured using a SYBRSafe exclusion assay (Figure 1C). SYBRSafe is a pDNA stain that emits a fluorescent signal upon intercalating between base pairs of DNA. However, if the DNA has already bound to the GET peptide, the fluorescent signal will be 
quenched. Previously, polymeric and polysaccharide-based gene delivery vectors have fully complexed pDNA into nanoparticles. [28, 30, 36] The gel electrophoresis study (Figure 1D) demonstrated that the pDNA is safely complexed with GET as the negatively charged pDNA is immobilized within the gel when complexed to GET at CR3, 4 and 5 (wells 5, 8 and 11 respectively). Furthermore, when incubated in serumcontaining media for $12 \mathrm{~h}$ at $37^{\circ} \mathrm{C}$, the pDNA remains complexed with GET (CR3: lane 6, CR4: lane 9, CR5: lane 12) and the complexation is stable even following incubation with DNase for $4 \mathrm{~h}$ at $37^{\circ} \mathrm{C}$ (CR3: lane 7, CR4: lane 10, CR5: lane 13). This is in contrast to uncomplexed pDNA which runs towards the positively charged anode at the end of the gel (lane 2) and is completely denatured by DNase (lane 4). 


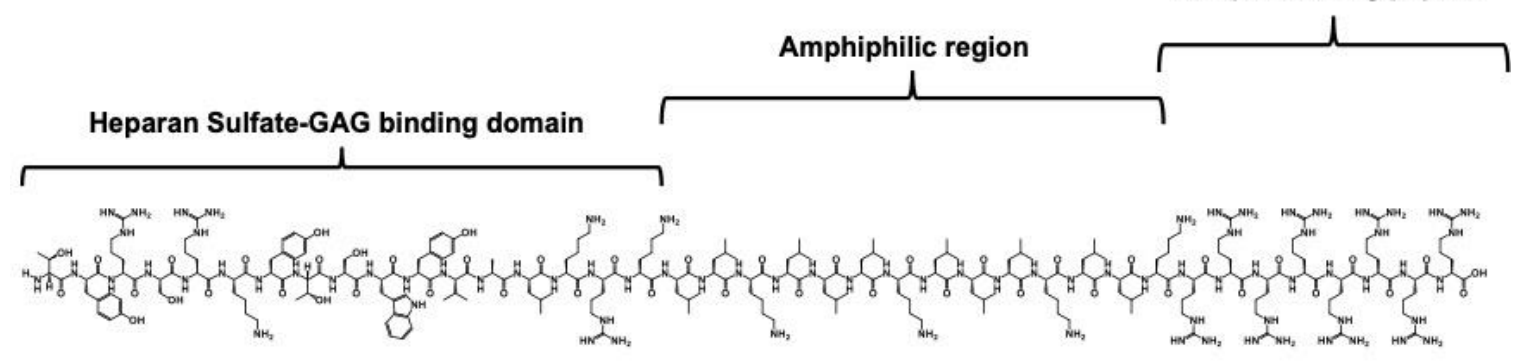

T Y R S R K Y T S W Y V A L K R K L L K L L L K L L L K L L K R R R R R R R

\section{F (FGF2B)}

R (8R)
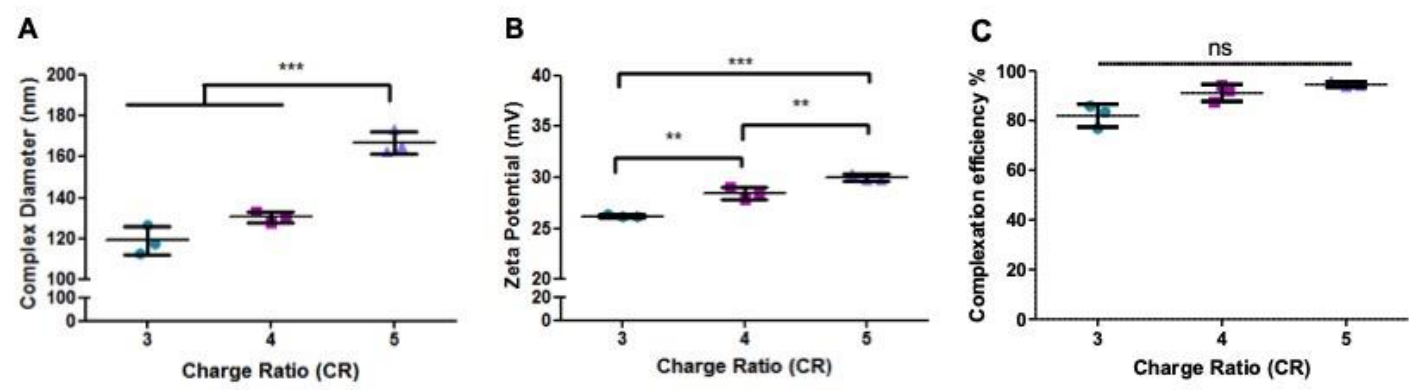

\section{D}

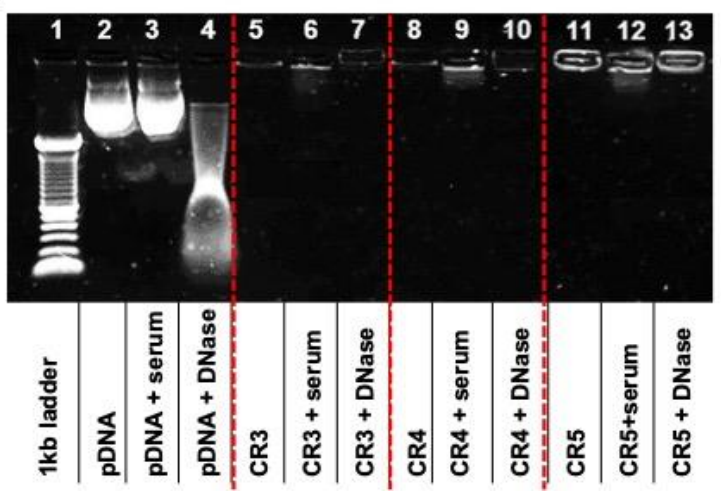

Figure 1. Physicochemical characterisation of GET-pDNA complexes. The GET peptide contains three segments, a heparan sulfate-GAG binding domain, an amphiphilic region which binds to pDNA, and a cell penetrating peptide domain to facilitate cell entry. The GET-pDNA complexes $(2 \mu \mathrm{g}$ pDNA) had an average diameter of $100-160 \mathrm{~nm}$ as shown by DLS (A). The zeta potential of GET-pDNA complexes increased with increasing CR from approximately $25 \mathrm{mV}$ (CR3) to $30 \mathrm{mV}$ at CR5 (B). The complexation efficiency was $82-95 \%$ as measured using a SYBRSafe exclusion assay (C) and this level of complexation was sufficient to protect the pDNA from degradation when challenged with serum for $12 \mathrm{~h}$ or DNase for $4 \mathrm{~h}$ (D). 1 - Ladder; 2 - pDNA alone; 3 - pDNA alone in serum; 4 - pDNA alone in DNase; 5 - GET-pDNA at CR3; 6 - GET-pDNA at CR3 in serum; 7 - GET-pDNA at CR3 in DNase; 8 - GET-pDNA at CR4; 9 GET-pDNA at CR4 in serum; 10 - GET-pDNA at CR4 in DNase; 11 - GET-pDNA at CR5; 12 - GETpDNA at CR5 in serum; 13 - GET-pDNA at CR5 in DNase. Data plotted represents mean \pm SD where $n=3$. One-way ANOVA followed by Tukey post hoc analysis was performed and $* *$ indicates $p<0.01$ while $* * *$ indicates $\mathrm{p}<0.001$. 
To confirm that the addition of the GAG-binding domain is indeed helping with transfection, each individual component of the GET peptide, namely F (FGF2B; the heparan sulfate-binding domain), L (LK15; the nucleic acid interaction sequence) and R (8R; the octaarginine cell penetrating peptide sequence), as well as dual combinations; FL, FR and LR, were complexed pGFP and the percentage of GFP+ cells was quantified after 3 days and compared to FLR at CR3. Mesenchymal stem cells (MSCs) were chosen for the optimization process as they represent a 'difficult-to-transfect' primary cell type. [49, 50] Figure $\mathbf{2 A}$ clearly shows that the addition of the GAG-binding domain significantly enhances transfection efficiency by approximately $30 \%$. The next best efficiency was with LR at $8.2 \pm 0.8 \%$. The relatively low efficiency of LR is due to the low dose of $8 \mathrm{R}$ used and highlights that the addition of the GAG-binding domain improves intracellular translocation.

As all three formulations of GET-pDNA (CR3, CR4 and CR5) possessed excellent physicochemical characteristics, the next step was to compare the transfection efficiency and biocompatibility of GET with a commercially available gold standard non-viral vector, namely Lipofectamine ${ }^{\circledR} 3000$ (Biosciences, Ireland). While Lipofectamine ${ }^{\circledR}$ 3000 had the highest transfection efficiency at $72.3 \pm 1.9 \%$, transfection efficiency was also high in GET-pGFP transfected cells at all CRs reaching efficiencies of $48.8 \pm 7.7 \%$, $62 \pm 5 \%$ and $42.8 \pm 5.3 \%$ for CR3, 4 and 5 respectively which is exceptionally high for a non-viral vector particularly in stem cells (Figure 2B). Indeed, there was no statistically significant difference between the transfection efficiency of GET at CR4 versus Lipofectamine ${ }^{\circledR} 3000$.

As well as being efficient, it is critical that gene delivery vectors do not induce significant cytotoxicity. In general, non-viral vectors tend to have a better safety profile than viral gene delivery vectors, [51] however, some lipid and polymer-based vectors have been shown to cause significant cytotoxicity. An MTT assay was used to measure cell metabolic activity post-transfection and compared to untransfected cells serving as the 100\% viable control. As shown in Figure 2C, cell metabolic activity in GET transfected cells was not significantly different to the control 3 days post-transfection with cell viability of $92.8 \pm 18 \%, 90 \pm 0.5 \%$ and $82 \pm 14.7 \%$ respectively for CR3, 4 and 5 . 
Lipofectamine ${ }^{\circledR} 3000$ transfected cells had a cell viability of $64 \pm 15.6 \%$ which, while not as bad as what has been reported in the past with other lipid-based vectors, was significantly lower than GET at CR4, further highlighting the potential of this vector.

It is also important to know the transfection dynamics of a gene delivery vector over time. Figure 2D shows representative images of cells at 1, 3, 7, and 14 days post-transfection with GET-pGFP. GFP positive cells are evident following transfection at CR3, 4 and 5 at all time-points. These cells were then removed from the wells and fixed before being analyzed using flow cytometry which paints a clearer picture of the transfection efficiency and GFP expression dynamics (Figure 2E). It surpasses transfection efficiencies reported with many commercially available vectors such as Lipofectamine ${ }^{\circledR}$ 2000, [52-54] PEI, [28, 55] chitosan, [30, 56] as well as CPPs, [57, 58] and other novel peptide-based macromolecular structures such as PAMAM dendrimers and star-shaped and hyperbranched polymers, $[36,59]$ by up to $20 \%$. Transfection peaked at day 3 at all $\mathrm{CR}$ and the transfection was transient with a gradual decrease to approximately $40 \pm 5 \%$ by day 7 and $25 \pm 6 \%$ by day 14 . Though not desirable when long-term gene correction is required, transient gene expression is ideal for tissue engineering applications as it allows for controllable over-expression of therapeutic proteins for a pre-determined amount of time to induce repair.

The cell-penetrating peptide in GET is poly-arginine (8R), an essential amino acid for tissue growth that has been shown to enhance cell proliferation. [60-62] In this study, cell proliferation rate was not affected, either positively or negatively, following treatment with GET-pGFP between transfected and untransfected cells up to 14 days posttransfection (Figure 2F). This is likely due to the lower concentration of $8 \mathrm{R}$ required when used in combination with the FGF2B-based peptide sequence and indicates that GET-pDNA nanoparticles are highly efficient for gene delivery with minimal disruption to the cell cycle.

It is important to note that all transfections presented in Figure $\mathbf{2}$ were carried out in serum-containing media. Many commercially available gene delivery vectors, including Lipofectamine ${ }^{\circledR} 3000$, work best in serum-free media, thus subjecting cells to unnatural serum starvation, which cannot be replicated in vivo. As GET-pDNA nanoparticles are 
efficient in the presence of serum, the translational potential of this vector is even more impressive.
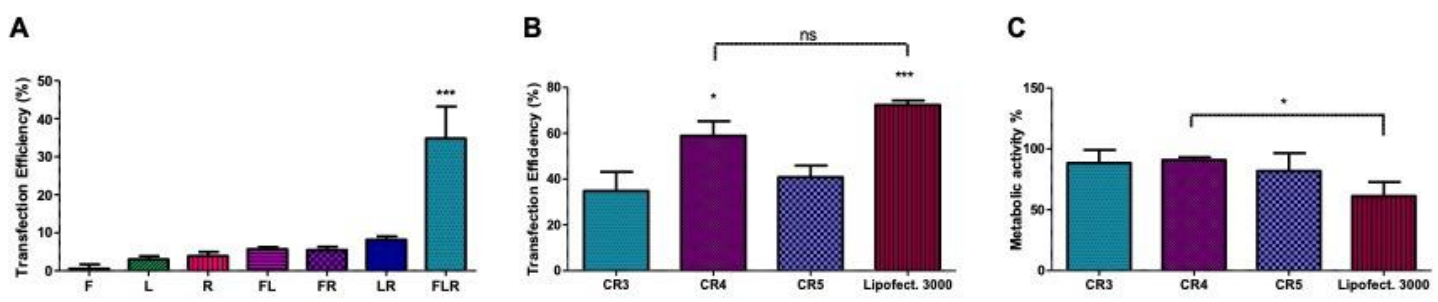
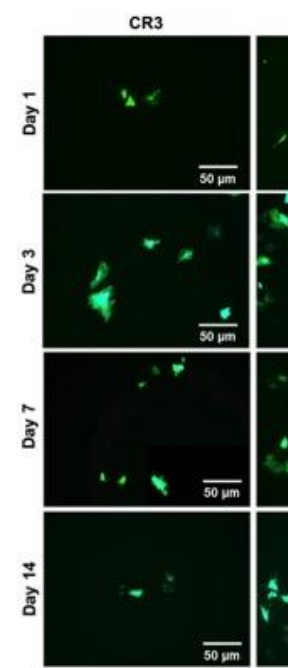
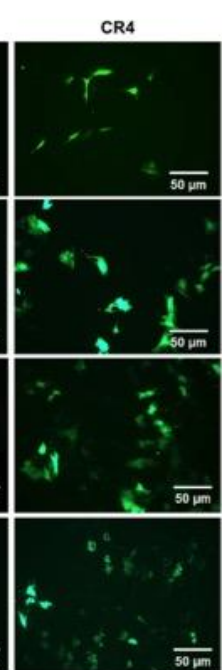

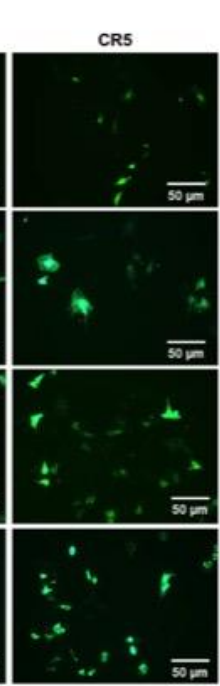

E
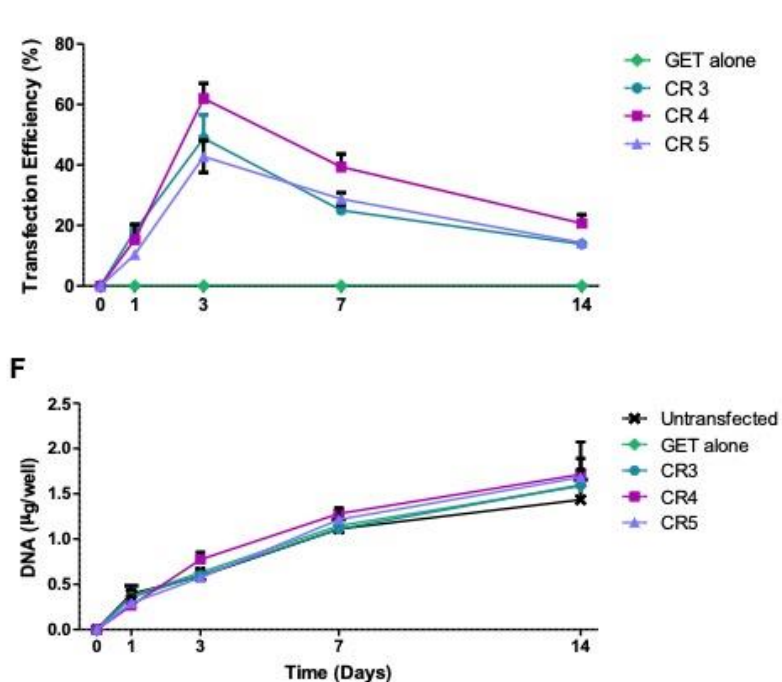

Figure 2. Effect of CR on transfection efficiency. Transfection efficiency of each component of the GET peptide was compared $(2 \mu \mathrm{g}$ pGFP) to showing that addition of the GAG-binding domain significantly improved transfection efficiency (A). CR4 induced significantly higher transfection efficiency than CR3 and $5(\mathrm{p}<0.05)$. Lipofectamine ${ }^{\circledR} 3000$ also induced significantly higher GFP expression than CR3 and 5 $(p<0.001)$ but was not significantly different to CR4 (B). Cell metabolic activity was higher in cells transfected with GET compared to Lipofectamine ${ }^{\circledR} 3000$, significantly so versus GET-pGFP at CR4 (C). Long-term transfection efficiency of GET-pGFP at CR 3, 4 and 5 (2 $\mu \mathrm{g}$ pGFP) was assessed using fluorescent microscopy (D). Green cells indicate positive transfection. The percentage of cells expressing GFP was quantified using flow cytometry (E). Cell viability post-transfection was measured using DNA quantification as a marker of cell proliferation $(\mathrm{F})$. There was positive transfection at all CR and cell proliferation remained normal with no significant difference compared to untransfected controls over time. Data plotted shows mean \pm standard deviation $(n=3)$ and $*$ indicates $p<0.05, * * p<0.01$ and $* * * p<0.001$.

We have shown that GET can protect pDNA from DNase degradation (Figure 1D) however; the salt concentration of physiological fluids can reduce electrostatic compulsion between nanoparticles resulting in aggregation and activation of the immune response. $[63,64]$ For this reason, we want to develop a scaffold-based delivery system that can both shield the GET-pDNA nanoparticles while also retaining the nanoparticles 
at the required site. The use of a biomaterial scaffold delivery system is advantageous, especially in tissue engineering applications where the scaffold functions in delivery and also provides a template for repair. The composition of the scaffold is important when considering the target tissue and within our lab we have developed a series of collagenbased scaffolds designed to mimic the native extracellular matrix of many tissues while allowing for cell infiltration, proliferation and in some cases, differentiation. [40-42, 65, 66] Moreover, these scaffolds can be manufactured into a variety of shapes to fit specific tissues. [67-69] In order to test the versatility of the GET peptide for pDNA delivery; this study involved incorporating GET-pDNA nanoparticles into four different collagen-based scaffolds, namely, collagen, collagen chondroitin sulfate (CCS), collagen hyaluronic acid (CHyA) and collagen hydroxyapatite (CHA). Collagen and CCS scaffolds are applicable for multiple tissues such as bone, cartilage, skin and heart valve among others. [70-72] CHyA has successfully been applied for use in cartilage, respiratory and nerve tissue engineering [41, 68, 73-75] while CHA was designed to mimic bone tissue and this particular scaffold has achieved CE approval in Europe and is in use in human patients. [42, 76-78] GET-pDNA nanoparticles were successfully and homogenously incorporated into each scaffold type as can be seen in SEM micrographs in Figure 3 Ai-Di. MSCs proliferated well on all scaffolds and no significant difference in cell number was observed over 28 days when the GET gene-activated scaffold was compared to gene-free controls (Figure 3 Aii-Dii). When MSCs were cultured on the gene-activated scaffolds, transgene expression was rapid and high peaking at approximately day 7 with $6 \times 10^{5} \pm$ $3.4 \times 10^{4}$ RLU at CR4 in all but the CHA scaffold (Figure 3 Aiii-Diii). Luciferase expression was sustained for 21-28 days post-transfection with no significant difference between CR3, CR4 or CR5. Interestingly, transfection was lowest on the CHA scaffold reaching a peak of approximately $1 \times 10^{5} \pm 1.6 \times 10^{4}$ which is in line with previous results using different vectors. [30] Further studies have shown that hydroxyapatite binds to many factors and slows their release (Walsh and Raftery et. al. under review), which, in the case of expressed growth factors, ultimately enhanced bioactivity. 


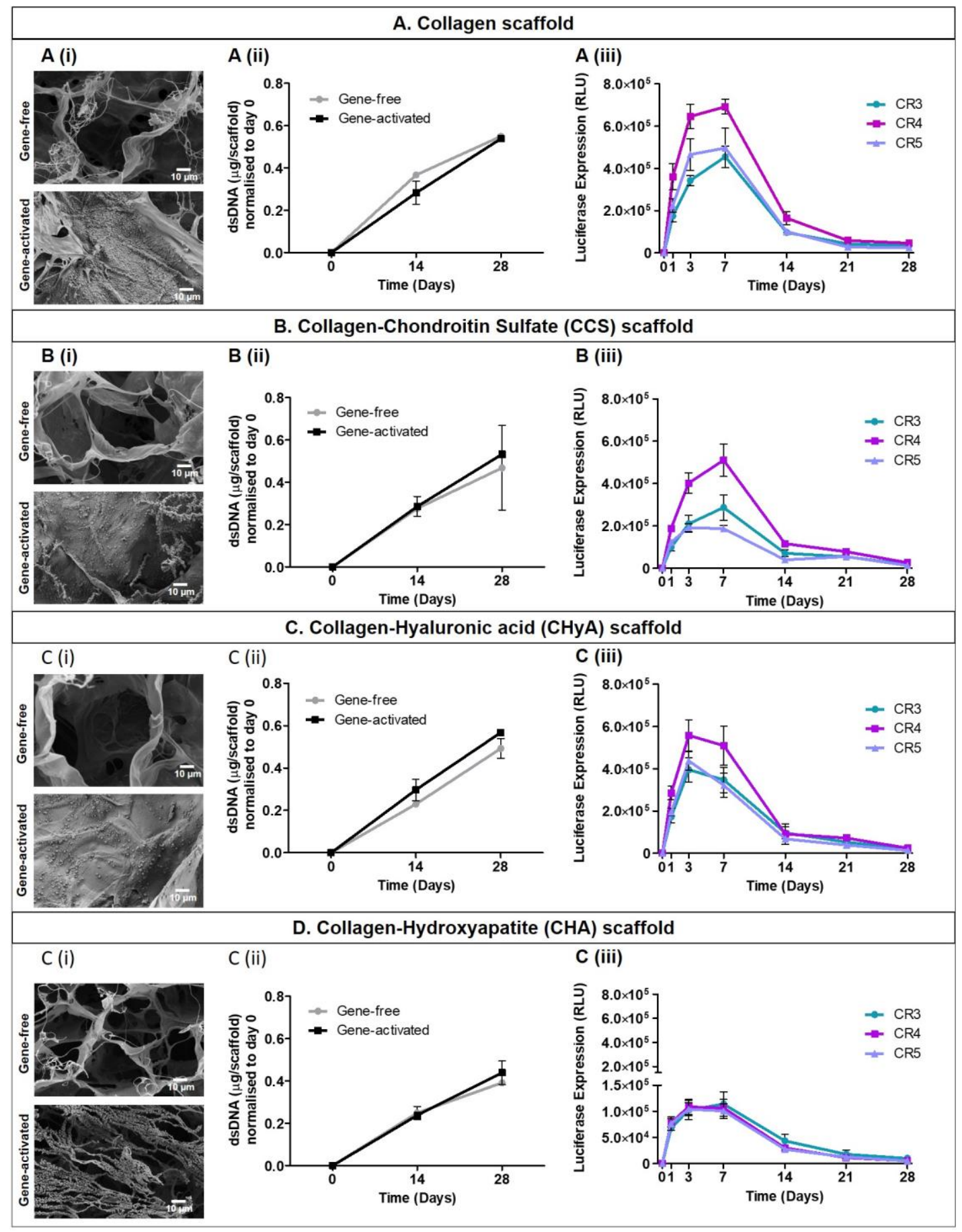

Figure 3. Effect of GET-activated scaffolds on MSC proliferation and comparison of transfection efficiency. GET-pDNA complexes at CR3, 4 and 5 ( $2 \mu \mathrm{g}$ pDNA) were incorporated into four different scaffolds; collagen alone (A), collagen-chondroitin sulfate (CCS) (B), collagen hyaluronic acid (CHyA) (C) and collagen hydroxyapatite (CHA) (D) and imaged using scanning electron microscopy. Representative images shown in A(i)-D(i) and show homogenous distribution of particles within the scaffolds. Cell proliferation on gene-activated scaffolds was not affected with the presence of GET-pDNA (CR5; $2 \mu \mathrm{g}$ pGLuc) relative to gene-free controls (A(ii)-D(ii)). Relative Gaussia Luciferase gene expression was monitored over time from MSCs seeded onto GET-pGLuc-activated scaffolds at CR 3, 4 and $5(2 \mu \mathrm{g}$ pGLuc) (A(iii)-D(iii)). Transgene expression is sustained for up to 28 days and a CR of 4 appears to be optimal. Data plotted shows mean \pm standard deviation $(n=3)$. 
Having established that GET-pDNA nanoparticles can be incorporated into different types of collagen-based scaffolds and maintain their high transfection efficiency, the next step was to determine if the gene-activated scaffolds were capable of transfecting endogenous cells when implanted acellularly in vivo, thus confirming the translational applicability of the system. For this study the collagen chondroitin sulfate (CCS) scaffold was used as it is arguably the most versatile of the scaffolds described earlier, having been used for bone, cartilage, skin and heart valve applications previously. [41, 71, 72, 79] The collagen hydroxyapatite (CHA) scaffold was also tested as it has been successfully used for bone repair in small and large animal models and is currently in use in human patients. [77, 78, 80] The reporter gene encoding Gaussia Luciferase (pGLuc) was used as it allows transgene expression to be monitored over time using live in vivo luminescence imaging software. The use of live bioluminescence imaging is a validated and consistent method of evaluating transcription and translation of genes by host cells after in vivo delivery and is a reliable tool for measuring biodistribution of the substrate. [81] As before, the GET-pDNA nanoparticles were incorporated into the scaffold, forming gene-activated scaffolds, before implantation subcutaneously on the dorsum of male Wistar rats. As the transfection efficiencies of GET-pDNA at CR3, 4 or 5 were similar in in vitro culture, all CRs were tested in vivo and bioluminescence was read at day 3, 7 and 14 post-implantation. What is immediately obvious is that luciferase expression is localised at the site of implantation and there was minimal evidence of expression elsewhere in the animals (Figure 4). There is background bioluminescence evident in the empty controls due to injection of coelenterazine but this was significantly lower than GET-pGLuc-activated scaffolds and was subtracted from the test groups. This result signifies that the scaffold-based gene delivery system was capable of retaining the GET-pGLuc nanoparticles at the site of implantation and indicates that this is a safe method for gene delivery as the risk of off-target affects was negated. When the intensity of bioluminescence was quantified, the peak in transfection efficiency occurred at day 3 and 7 , similar to in vitro results, followed by a gradual decline. Interestingly, luciferase expression was higher on the CHA scaffold reaching $5.9 \times 10^{5} \pm 2 \times 10^{5}$ by day 7 at CR4 (Figure 4B) when compared to the CCS scaffold 3.9 $\times 10^{5} \pm 1.5 \times 10^{5}$ (Figure 4A). This is in direct contrast to the in vitro luciferase expression results (Figure 3 B versus D) but is 
likely due to the faster degradation rate of the scaffolds in vivo compared to in vitro and supports our hypothesis that expressed proteins become sequestered by the hydroxyapatite particles in the CHA scaffold and actually, transfection efficiency on this scaffold is similar to the others. Encouragingly, luciferase expression was maintained up to day 14 in the CHA scaffolds particularly those carrying GET-pGLuc at CR4 which indicates that as well as providing a safe delivery method, the scaffold is also functioning in protecting the GET-pGLuc nanoparticles from degradation. This is extremely important as unmodified poly-arginine-based CPPs tend to get excreted rapidly when administered systemically. [23, 82] Furthermore, in studies where pDNA was injected interperitoneally without a vector, the pDNA accumulated in the liver and kidneys with a peak in transgene expression after $24 \mathrm{~h}$ followed by a rapid decline. [81] From the results presented in Figures 1-4, GET-pDNA nanoparticles carrying $2 \mu \mathrm{g}$ of pDNA at CR4 performed the best and was designated as the optimal formulation and used in all further experiments. Encouragingly, CR4 performed well throughout the earlier in vitro experiments in $2 \mathrm{D}$ monolayer and in $3 \mathrm{D}$ culture, validating these methods used to test non-viral gene delivery vectors. 

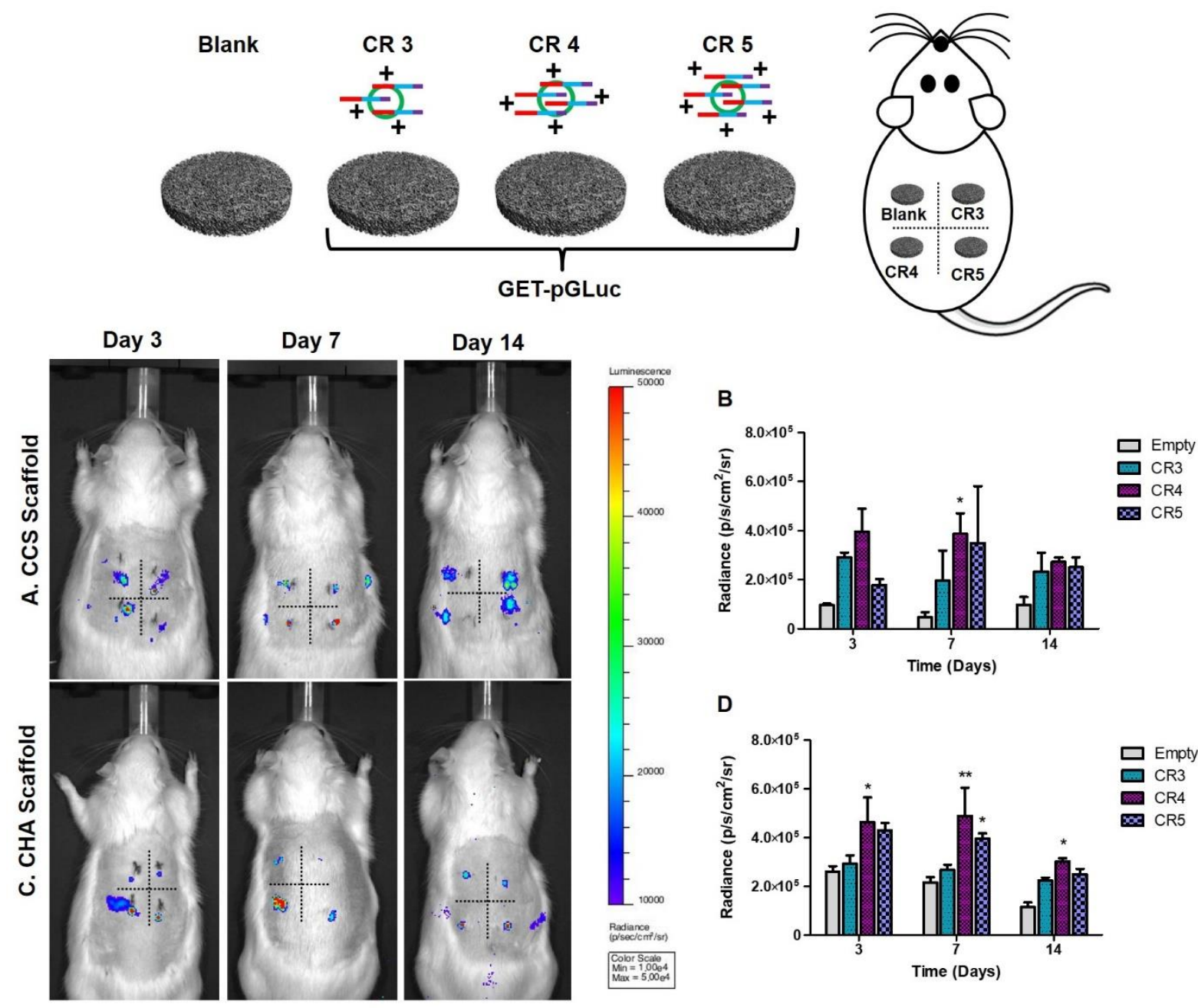

Figure 4. Efficacy of GET-pDNA activated scaffolds in vivo. In vivo transfection efficiency and biodistribution following implantation of cell-free GET-pGLuc activated CCS scaffolds (A) and CHA

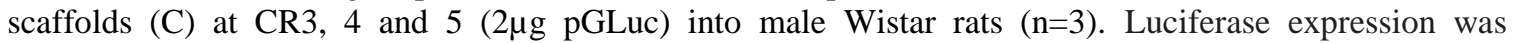
monitored over time by emitted light displayed as a pseudo-color image overlaying a black-and-white photograph of each rat at days 3, 7 and 14 post-implantation. Luciferase expression appears localized to implant site at transfection is transient. Luminesence signal intensity is represented by radiance $\left(\mathrm{p} / \mathrm{sec} / \mathrm{cm}^{2} / \mathrm{sr}\right)$ and was quantified using Perkin Elmer Living Image software. GET-pGLuc at CR4 induced significantly higher luciferase expression by cells on the CCS scaffold at day 7 (B) and at each time-point on the CHA scaffold (D). and transfection is transient peaking at day 3. GET-pGLuc complexes at CR4 $(2 \mu \mathrm{g}$ pGLuc) induce the most transgene expression. Data plotted shows mean \pm SEM where $n=3$. * represents $\mathrm{p}<0.05$ and $* * \mathrm{p}<0.01$

To further emphasize the versatility of the GET peptide as a gene delivery vector, GETpGFP nanoparticles, formulated at CR4 carrying $2 \mu \mathrm{g}$ of pGFP, were delivered to a series of different cell types representing different tissues from all three germ layers. This is important as many gene delivery vectors show excellent transfection efficiency characteristics in specific cell lines such as HeLa, NIH3t3 or HEK293T cells but not in 
primary cells - which limits the translational applicability of the vector. Furthermore, some vectors can be cell specific. Human MSCs are a notoriously difficult cell type to transfect but with GET-pGFP nanoparticles the transfection efficiency was approximately $28.5 \pm 1.8 \%$ at day 3, following a similar trend to what was observed in rat MSCs (Figure 5A(i) and (ii)). This is higher than what has previously been reported in our group using PEI, a gold-standard non-viral gene delivery vector. [83] To represent bone cells, a wellestablished osteoblast cell line, MC3T3-E1, was used and transfection efficiency reached approximately $20.7 \pm 4 \%$ at day 3 (Figure $\mathbf{5 B}$ (i) and (ii)). Yamano et al. compared the transfection efficiency of six different commercially available gene delivery vectors on MC3T3-E1 cells including Arrest-In ${ }^{\mathrm{TM}}$, ExpressFect ${ }^{\mathrm{TM}}$, FuGene ${ }^{\circ}$ HD, jetPEI®, Lipofectamine $\AA 2000$, and SuperFect ${ }^{\circledR}$ although different methods were used to determine transfection efficiency, namely luciferase expression rather than FACS analysis of GFP+ cells, making it difficult to draw comparisons. [84] The same study by Yamano and colleagues also compared the transfection efficiency of these well-known vectors in $\mathrm{C} 2 \mathrm{C} 12$ cells, a mouse myoblast cell line chosen to represent muscle in the experiment presented in Figure 5D(i) and (ii). Unlike Yamono's results, in our study C2C12 cells were transfected more readily than MC3T3-E1 cells with transfection efficiencies of $43.8 \pm 2.8 \%$ at day 7 . Primary human articular chondrocytes have been transduced using a number of different viral vectors including retroviral, lentiviral, adenoviral and adeno-associated viral vectors. However, they are less commonly transfected using non-viral vectors. FuGene® 6 has a reported transfection efficiency of up to $20 \%$ when used with hyaluronidase treatment which is comparable to the $20 \pm 1.7 \%$ transfection efficiency achieved with GET in this study (Figure 5C(i) and (ii)). [85] Nucleofection has been used to achieve transfection efficiencies of up to $70 \%$, albeit with $20 \%$ cell death post-treatment, and oligofectamine delivering a 5 times higher pDNA dose than that reported in this study had a transfection efficiency of approximately $40 \%$ [86] which indicates that GET can be further optimized for hAC transfection. In a study by Dickens et al. in 2010, transfection efficiency of five vectors; Effectene ${ }^{\circledR}$, FuGene ${ }^{\circledR}$ HD, Lipofectin $®$, PEI and nucleofection, were compared following transfection of human dermal fibroblasts (hDFs) and human endothelial progenitor cells (hEPCs) derived from peripheral blood. [87] FACS analysis of GFP expression 48h post- 
transfection showed efficiencies of approximately $10 \%$ with each vector while nucleofection resulted in about $45 \%$ of cells expressing the transgene. The transfection efficiency of these vectors in EPCs was very variable, reaching $45 \%$ with Effectene ${ }^{\circledR}$ and 0\% when PEI was used. This study compares favorably with our results which show a transfection efficiency of $16.1 \pm 1.5 \%$ in hDFs at day 3 (Figure 5 E(i) and (ii)) and $46.5 \pm 3.5 \%$ in human umbilical vein endothelial cells also at day 3 (Figure $\mathbf{5 F}$ (i) and (ii)), again comparable to commercially available vectors. HL-1 cells are a cardiomyocyte cell line which have been successfully transfected with Lipofectamine ${ }^{\circledR} 2000$ carrying siRNA previously [88] resulting in approximately 68\% silencing of the target gene. We could not find any reports of pDNA delivery to HL-1 cells (Figure 5G(i) and (ii)), or Ne4C cells (Figure 5H(i) and (ii)), a mouse neuroectodermal cell line with potential for neurogenesis and gliogenesis, where transfection efficiency was quantified in a way that can be compared to this study. However, the $15.1 \pm 3.5 \%$ and $33 \pm 2.8 \%$ is relatively high and demonstrates that GET-pDNA particles are efficient in many different cell types.

Within our own lab we have compared GET-pDNA to chitosan (NovaFect ${ }^{\circledR}$; Mw 7.3kDa, N/P 20) and PEI (Mw 25kDa, N/P 7) as well as Lipofectamine ${ }^{\circledR} 3000$ shown in Figure 2, and found that GET was transfected approximately $20 \%$ more cells when delivering $2 \mu \mathrm{g}$ of pGFP to rMSCs. Taken together, this study demonstrates that without any further optimization or modifications, GET-pDNA nanoparticles have transfection efficiencies equal to or, in many cases, greater than a number of commercially available gene delivery vectors. 

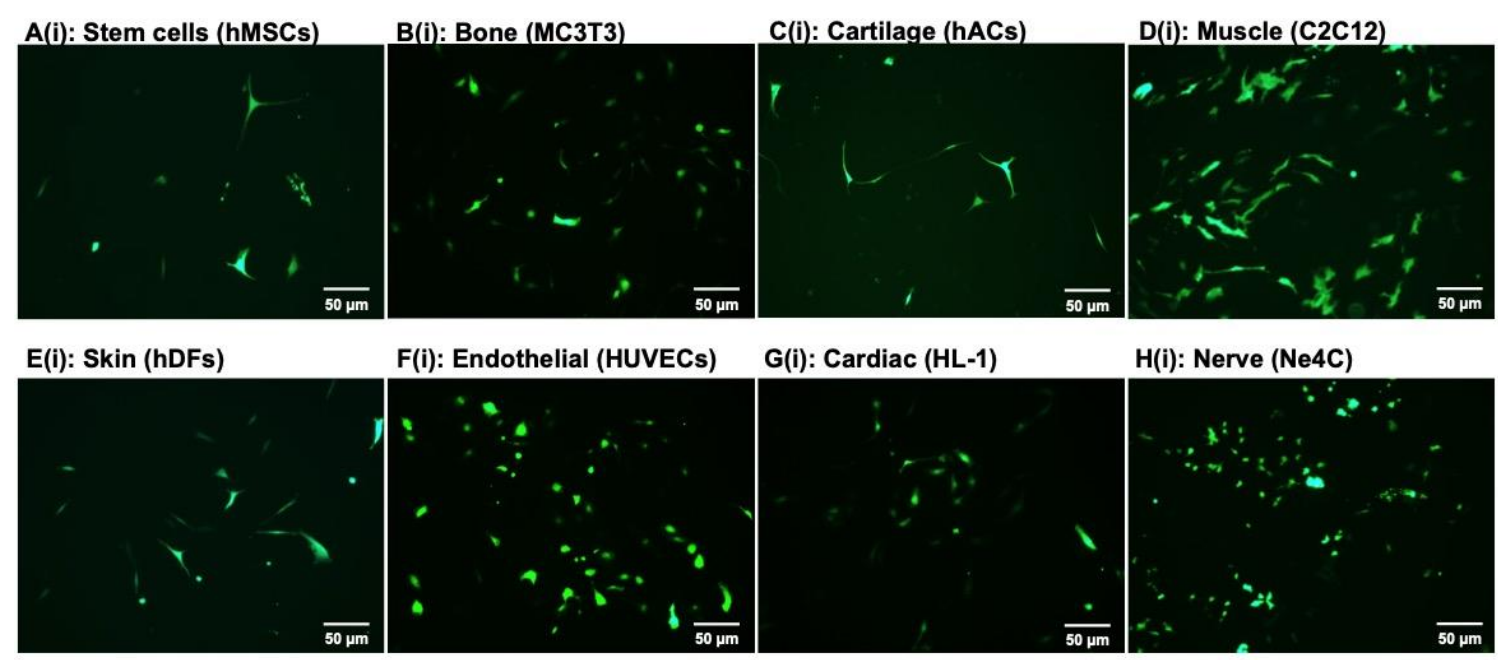

F(i): Endothelial (HUVECs)

G(i): Cardiac (HL-1)

H(i): Nerve (Ne4C)

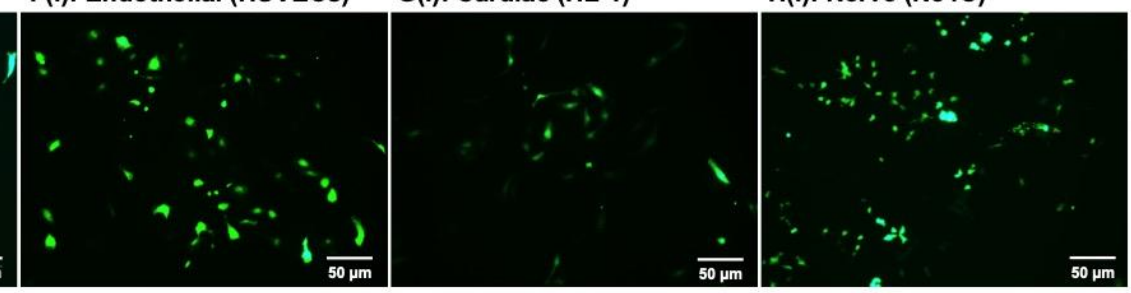

A(ii): Stem cells (hMSCs)
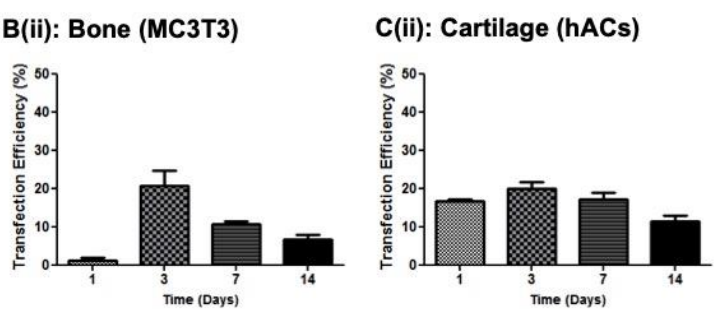

D(ii): Muscle (C2C12)

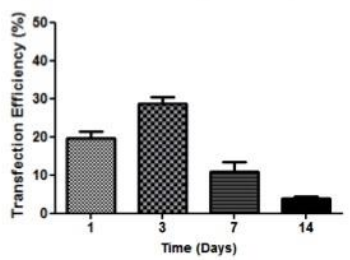

F(ii): Endothelial (HUVECs)

G(ii): Cardiac (HL-1)

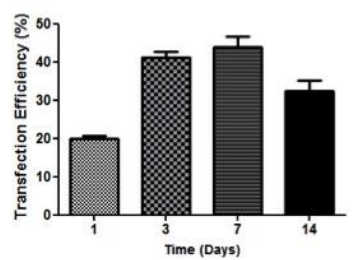

E(ii): Skin (hDFs)
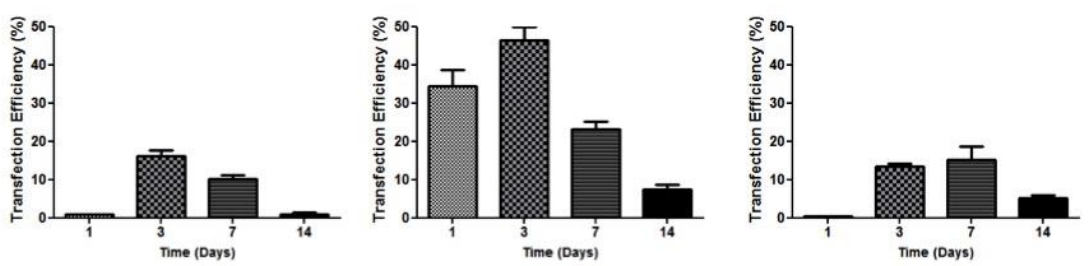

H(ii): Nerve (Ne4C)

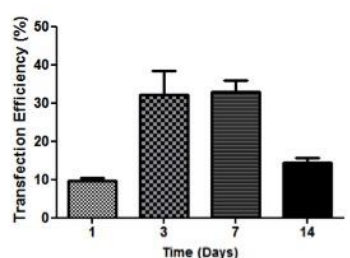

Figure 5. Assessment of GET-pGFP transfection efficiency in various cell types. GET-pGFP $(2 \mu \mathrm{g}$ pDNA dose at CR4) proved to be highly versatile with positive transfection in eight different cell types. Images A(i)-H(i) depict GFP positive cells on day 3 post-transfection. Graphs A(ii)-H(ii) display the corresponding quantification of GFP positive cells on days 1,3,7 and 14 which was analyzed using FACS. Data plotted represents mean \pm standard deviation $(n=3)$.

\subsection{Development of a GET-pDNA-activated scaffold for bone regeneration}

The clinical translation of bioactive scaffolds for the treatment of large segmental bone defects has remained a challenge due to safety and efficacy concerns as well as prohibitive costs. The design of an implantable, biocompatible and resorbable device, which can fill the defect space, allow for cell infiltration, differentiation and neovascularization, while also recapitulating the natural repair process and inducing cells to lay down new bone tissue, would alleviate the problems with existing treatments. As 
shown in Figure 4, gene-activated scaffolds can allow for sustained release of therapeutic pDNA to cells as they infiltrate the scaffold thereby prolonging the therapeutic timeline without additional dosing and also limiting off-target side effects. In addition, by using the osteoconductive CHA scaffold, infiltrating cells will be provided with an extracellular matrix similar to native bone tissue. The first use of a gene-activated scaffold for bone repair was reported in 1996 using a rat femoral defect model [27] while 20 years later the first report of a single patient clinical trial using a gene-activated scaffold to repair a nonunion mandibular defect was published. [89] In the human trial plasmid DNA was incorporated into a collagen hydroxyapatite scaffold without a gene delivery vector and at a very high dose (1 mg of pDNA). Encouragingly, no inflammation or adverse events were reported although the effectiveness of the treatment was limited. We believe that the use of a gene delivery vector to protect the pDNA from degradation and reduce the pDNA dose required will further enhance the repair process.

Previous work has shown that by combining delivery of pDNA encoding bone morphogenetic protein (BMP) and vascular endothelial growth factor (VEGF) can induce rapid repair of critical-sized bone defects. [32, 90, 91] Bone morphogenetic protein-2 (BMP-2) is one of the most potent inducers of bone formation and has been used to stimulate bone formation clinically in spinal fusion procedures. [92] Neo-angiogenesis is also extremely important in bone repair as damage to the vasculature can often lead to inadequate healing or non-union bone defects. In particular vascular endothelial growth factor (VEGF) plays a critical role in endochondral ossification, the process by which bone forms from a cartilaginous template in the embryo and in the growth plates of long bones. [93, 94] Indeed, many studies on fracture repair kinetics have shown that inhibition of VEGF can impair bone healing. [95] To create a direct comparison between the efficacy of GET-pDNA-activated scaffolds and previously developed gene-activated scaffolds, $[32,90]$ MSCs were transfected with GET-pBMP-2 (2 $\mu \mathrm{g}$ dose of pBMP-2) and GET-pVEGF ( $2 \mu \mathrm{g}$ dose of pVEGF), as well as a combination of pBMP-2 and pVEGF ( $1 \mu \mathrm{g}$ dose of each; total pDNA dose of $2 \mu \mathrm{g}$ ), termed GET-pDual. BMP-2 protein expression levels were increased following transfection with GET-pBMP-2 and GET-pDual but not with GET-pVEGF (Figure 6A) while conversely, VEGF protein expression was increased following transfection with GET-pVEGF and GET-pDual but 
not with GET-pBMP-2 (Figure 6B). This study simply shows that protein expression can be easily manipulated using GET-pDNA nanoparticles and the earlier transfection efficiencies observed when reporter pDNA was delivered can be recapitulated when using therapeutic pDNA. To determine if these secreted proteins were having an osteoinductive effect on the MSCs, alkaline phosphatase (ALP) activity was measured 7 days post-transfection (Figure 6C) and calcium deposition was quantified after 14 days (Figure 6D). ALP activity was significantly increased in MSCs transfected with GETpBMP-2, GET-pVEGF and GET-pDual $(\mathrm{p}<0.001)$ and this translated to significantly increased calcium deposition by differentiated cells compared to untransfected cells and cells transfected with non-osteogenic GET-pGFP $(\mathrm{p}<0.05)$. These data compare favorably with previously published data using chitosan as a gene delivery vector and surpass data where PEI and nanohydroxyapatite was used to deliver these genes. [32, 33, 90]

When MSCs were seeded onto gene-activated scaffolds loaded with GET-pBMP-2 (2 $\mu \mathrm{g}$ dose of pBMP-2), GET-pVEGF (2 $\mu$ g dose of pVEGF), and GET-pDual (1 $\mu \mathrm{g}$ dose each of pBMP-2 and pVEGF; total pDNA dose of $2 \mu \mathrm{g}$ ) nanoparticles. A visible increase in mineralization was evident in scaffolds stained with alizarin red (Figure 6E) and when quantified, the amount of calcium produced by MSCs on each gene-activated scaffold was 3-4-fold higher than controls $(\mathrm{p}<0.001)$. The GET-pDual-activated scaffold induced significantly more calcium deposition than scaffolds carrying single genes $(\mathrm{p}<0.05)$ (Figure 6F). These data are comparable to previously published data on the CHA scaffold loaded with chitosan nanoparticles carrying both pBMP-2 and pVEGF with approximately $2000 \mu \mathrm{g}$ of calcium produced by cells [32] and $50 \%$ more than that reported when a nanohydroxyapatite vector was used. [90] 

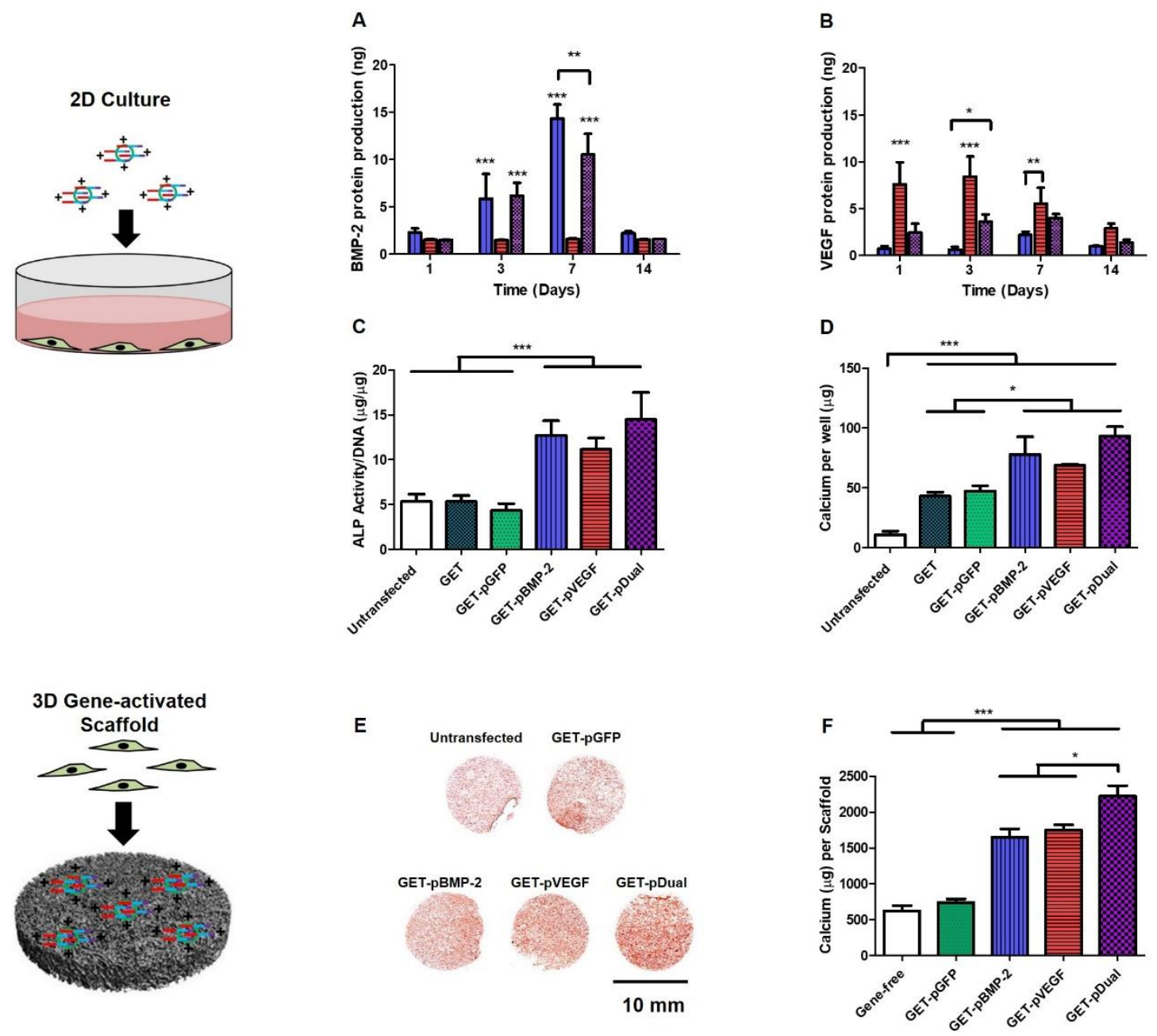

Figure 6. Quantification of therapeutic protein production post-transfection and assessment of protein functionality in inducing MSC osteogenesis in 2D monolayer and on 3D CHA scaffolds in vitro. MSCs were transfected with GET-pBMP-2 ( $2 \mu \mathrm{g}$ pDNA dose), GET-pVEGF ( $2 \mu \mathrm{g}$ pDNA dose) or GET-pDual (1 $\mu \mathrm{g}$ pBMP-2 $+1 \mu \mathrm{g}$ pVEGF) and production of BMP-2 and VEGF proteins was monitored by ELISA at days 1, 3, 7 and 14 post-transfection. A) BMP-2 protein production was increased in cells transfected with GET-pBMP-2 and GET-pDual (A) while VEGF protein production was increased in cells transfected with GET-pVEGF and GET-pDual (B). ALP activity in MSCs was measured 7 days posttransfection and showed that transfection with GET-pBMP-2, GET-pVEGF, and GET-pDual caused a significant up-regulation in ALP activity compared to controls (C). D) Calcium deposition was quantified 14 days post-transfection. Each treatment induced cells to produce significantly more calcium than controls. When incorporated into CHA scaffolds, a gene-free scaffold was compared to CHA scaffolds loaded with GET-pGFP ( $2 \mu \mathrm{g}$ pDNA dose), GET-pBMP-2 ( $2 \mu \mathrm{g}$ pDNA dose), GET-pVEGF ( $2 \mu \mathrm{g}$ pDNA dose $)$ and GET-pDual $(1 \mu \mathrm{g}$ pBMP-2 + 1 $\mu \mathrm{g}$ pVEGF). Mineral deposition by cells was measured after 28 days by staining scaffolds using Alizarin red (E) and calcium deposition was quantified (F). Data plotted represents mean \pm SD where $n=3$. * represents $\mathrm{p}<0.05, * * \mathrm{p}<0.01$ and $* * *$ represents $\mathrm{p}<0.001$.

Having confirmed that the GET-pDNA-activated scaffold is effective in the delivery of reporter genes to host cells when implanted in vivo (Figure 4), and can induce an osteogenic response by MSCs in vitro (Figure 6), in order to investigate the potential for 
clinical translation of GET-pDNA-activated scaffolds, we chose a rat calvarial criticalsized bone defect model as a therapeutic target due to our laboratory's extensive expertise with this model - which serves as a rapid, high throughput method for in vivo evaluation of bone regeneration. [96] While GET-Dual-activated scaffolds performed significantly better than all other groups during in vitro testing, GET-pBMP-2 and GET-pVEGFactivated scaffolds also induced significantly more calcium deposition by MSCs compared to controls and were therefore also included in the in vivo assessment. We have previously shown that a $7 \mathrm{~mm}$ diameter represents a critical-sized defect in Wistar rats with a body weight of between 285-350 g. [32] One defect was created per animal and was either left empty (Empty defect), filled with a CHA scaffold without genes (Genefree), or CHA scaffolds loaded with GET-pBMP-2 nanoparticles (GET-pBMP-2; $2 \mu \mathrm{g}$ pDNA dose at CR4), GET-pVEGF nanoparticles (GET-pVEGF; $2 \mu \mathrm{g}$ pDNA dose at CR4) or GET-pBMP-2 and GET-pVEGF nanoparticles (GET-pDual; $1 \mu \mathrm{g}$ of each pDNA at CR4). As the CHA is scaffold is inherently osteoinductive due to the presence of hydroxyapatite particles, the gene-free scaffold is capable of inducing limited repair of a critical-sized defect at 4-8 weeks post-implantation $[32,33,97,98]$ but at 16 weeks postimplantation in a rabbit radial defect model, the CHA scaffold induced a similar level of repair as an autogenous bone graft. [78] To assess if the inclusion of GET-pDNA nanoparticles within the scaffold can accelerate bone formation over the gene-free CHA scaffold, the early time-point of 4 weeks was chosen in this study and microCT and histomorphometry were used to quantify new bone formation.

What is immediately clear from the 3D microCT reconstructions (Figure 7A) is that the empty defect showed very minimal repair after 4 weeks and the gene-free scaffold induced limited bone formation. Conversely, each GET-pDNA-activated scaffold induced large amounts of new bone formation with the GET-pDual-activated scaffold completely bridging the defect. When directly compared to previous studies in bone defect repair, GET-pDNA activated scaffolds were capable of doubling the amount of new bone formation in the same 4 week timeframe. [32] Interestingly, the GET-pVEGFactivated scaffold induced significantly more new bone formation compared to the GETpBMP-2-activated scaffold $(\mathrm{p}<0.01)$. This is in agreement with results from ours and other laboratories confirming the critical role an enhanced blood supply has in bone 
repair. [32, 94, 95] The histology and subsequent histomorphometry (Figure 7B) confirm these results with mature bone bridging the defect in the GET-pDual-activated scaffold and large areas of bone formation evident in the GET-pBMP-2 and GET-pVEGFactivated scaffolds and to a lesser extent, the gene-free scaffold. Thin fibrous tissue is all that is present within the empty defect. Again, when quantified, a similar trend to the microCT results is evident with GET-pBMP-2<GET-pVEGF<GET-pDual. VEGF plays a central role in neovascularization but also acts as a chemoattractant to osteoprogenitor cells such as MSCs and can drive osteogenesis, a phenomenon which may explain why the GET-pVEGF containing scaffolds performed so well compared to the more established pBMP-2 scaffolds. Furthermore, it has been shown that the presence of VEGF can make osteoprogenitor cells more sensitive to BMP-2, thus increasing the efficacy of BMP-2 over-expression, which may explain why the GET-pDual group outperforms GET-pVEGF and GET-pBMP-2 (p<0.001). [99]

To investigate if new blood vessel formation is indeed occurring in the pVEGF containing scaffolds, we stained for CD31, a marker of endothelial cells and quantified the number of new vessels found. In Figure 7C CD $31^{+}$endothelial cells are stained in red and the representative images confirm the hypothesis that the over-expression of VEGF at the defect site induced more blood vessel formation, which subsequently increases cell infiltration and new bone formation over GET-pBMP-2 scaffolds. When quantified, there were significantly more new blood vessels present in the pVEGF containing geneactivated scaffolds $(\mathrm{p}<0.001)$.

Taken together, these data show that the GET peptide fulfills all of the requirements for a gene delivery vector, being capable of efficient delivery of pDNA to a number of cell types form each of the three germ layers, including stem cells, while causing minimal cytotoxicity. When incorporated into a scaffold-based delivery device and implanted in vivo, the GET-pDNA activated scaffold allows for host cell infiltration, localized transfection and sustained, but ultimately transient, transgene expression. When used to deliver therapeutic genes, utilizing bone repair as an exemplar indication, low doses of both GET and pDNA were sufficient to induce MSC osteogenesis and finally when implanted in a critical-sized bone defect, complete repair of the defect was achieved in just four weeks in a defect that we know would not heal without intervention and takes 
approximately 12 weeks to heal with the scaffold alone. [78] In summary, the results from this study show that GET-mediated gene delivery represents an extremely exciting development for the field of gene therapy, and, by combining it with scaffold-based delivery systems offers potential tissue engineering solutions for a myriad of regenerative indications. 

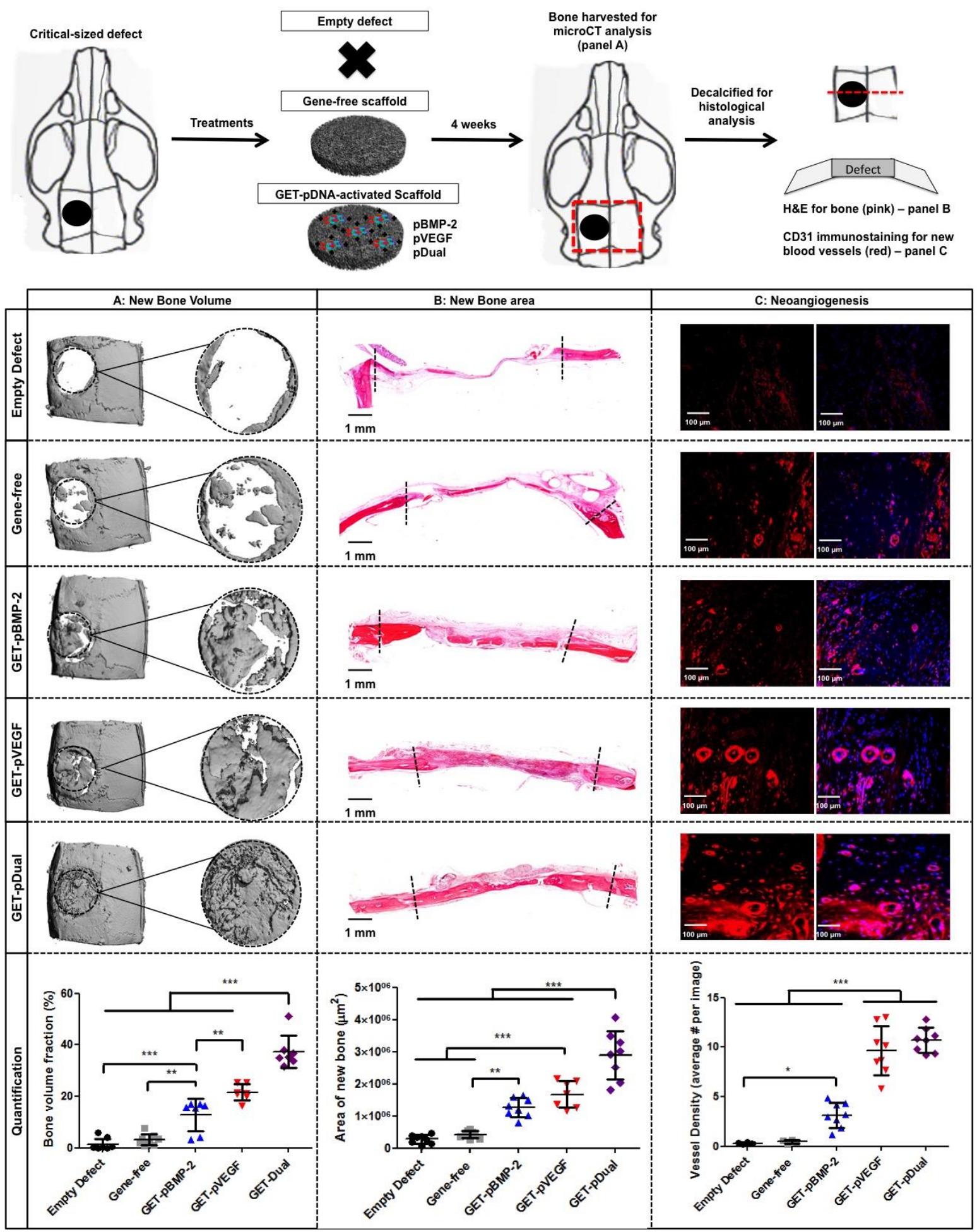

Figure 7. Micro-CT and histological analysis of bone repair in a critical-sized calvarial defect 4 weeks post-implantation. A) Representative microCT scans of harvested bone showing; empty defect, gene-free CHA scaffold, GET-pBMP-2 ( $2 \mu \mathrm{g}$ dose) activated CHA scaffold, GET-+pVEGF ( $2 \mu \mathrm{g}$ dose), and GETpDual $(1 \mu \mathrm{g}$ pDNA dose each of pBMP-2 and pVEGF) activated CHA scaffold. A $6 \mathrm{~mm}$ area at the center of the defect was used to quantify new bone volume (\% Bone volume fraction) displayed in graph A showing significantly enhanced bone formation in all treatment groups over controls with GET-pDual inducing the best repair $(* * * \mathrm{p}<0.001)$. B) Representative histological section of explants from calvarial 
defects at 4x. Histomorphological analysis confirmed that the GET-pDual activated scaffold significantly enhanced and accelerated new bone formation compared to all other groups after 4 weeks $(* * * p<0.001)$. C) Representative images of CD31-stained endothelial cells and over-lay with DAPI to show cell nuclei confirming presence of vessels. More vessels were visible in the defects treated with the GET-pVEGF and GET-pDual compared to controls and GET-pBMP-2 after 4 weeks indicating enhanced angiogenesis. The average number of vessels per image ( 3 images per section, 6 sections per animal, 8 animals $=18$ images per group) was quantified and showed that the defects treated with GET-pVEGF and GET-pDual significantly enhanced new vessel formation within the defect site confirming the crucial role of angiogenesis in bone regeneration. Data plotted represents mean \pm standard deviation $(n=8)$. One-way ANOVA followed by Tukey post hoc analysis was performed and $*$ represents $\mathrm{p}<0.05$, ** represents $\mathrm{p}<0.01$ and $* * *$ represents $\mathrm{p}<0.001$. 


\section{Conclusion}

Despite recent success in the field of gene therapy, there is currently no clinically approved non-viral gene delivery vector available, due to the difficulty in designing vectors capable of safely recapitulating viral vectors. However, non-viral vectors are generally easier to produce, less costly, and generally safer, making them extremely useful in therapies which do not require long-term changes to the genome, simply shortterm over-expression or silencing of a target sequence. This is particularly true in tissue engineering where short-term manipulation of cells can be sufficient to induce tissue regeneration. This study demonstrates that GET, a multidomain peptide containing both a cell binding sequence and a CPP, fulfills the requirements for the ideal gene delivery vector as it is capable of efficiently (62\%; comparable to Lipofectamine ${ }^{\circledR}$ 3000) and safely delivering pDNA to 'difficult-to-transfect' MSCs. When combined with biomaterial scaffolds, the GET-pDNA activated scaffolds allowed for host cell infiltration, localized transfection, and induced sustained, but overall, short-term changes in gene expression. When applied for the treatment of critical-sized bone defects in vivo, the GET-pDNA-activated scaffold system essentially acts as a single-treatment therapeutic factory by inducing host cells to produce therapeutic osteogenic (BMP-2) and angiogenic (VEGF) proteins at physiological levels, resulting in more bone formation at an earlier time-point than studies delivering recombinant proteins, [98] without the adverse side effects and at a fraction of the cost. GET was also shown to be highly versatile, capable of transfecting multiple cell types on different biomaterial substrates indicating widespread translational potential in a range of tissue engineering applications. 


\section{Acknowledgements}

This work was funded by Science Foundation Ireland (SFI) through the Advanced Materials and Bioengineering Research (AMBER) Centre (SFI/12/RC/2278). JED, GO \& KMS acknowledge the support the Medical Research Council [grant number MR/K026682/1]; the Engineering and Physical Sciences Research Council; and the Biotechnology and Biological Sciences Research Council which formed the UK Regenerative Medicine Platform Hub “Acellular Approaches for Therapeutic Delivery”.

\section{Declarations of interest: none}

\section{Data availability}

The raw/processed data required to reproduce these findings cannot be shared at this time as the data also forms part of an ongoing study. 


\section{References}

[1] W. Sun, J. Lee, S. Zhang, C. Benyshek, M.R. Dokmeci, A. Khademhosseini, Engineering Precision Medicine, Advanced Science (2018) 1801039.

[2] R. Juliano, X. Ming, K. Carver, B. Laing, Cellular uptake and intracellular trafficking of oligonucleotides: implications for oligonucleotide pharmacology, Nucleic acid therapeutics 24(2) (2014) 101-113.

[3] S.L. Ginn, A.K. Amaya, I.E. Alexander, M. Edelstein, M.R. Abedi, Gene therapy clinical trials worldwide to 2017: An update, J. Gene Med. 20(5) (2018) e3015.

[4] C.H. Evans, S.C. Ghivizzani, P.D. Robbins, Arthritis Gene Therapy Approved in Korea, JAAOSJournal of the American Academy of Orthopaedic Surgeons 26(2) (2018) e36-e38.

[5] J. Cherian, J. Parvizi, D. Bramlet, K. Lee, D. Romness, M. Mont, Preliminary results of a phase II randomized study to determine the efficacy and safety of genetically engineered allogeneic human chondrocytes expressing TGF- $\beta 1$ in patients with grade 3 chronic degenerative joint disease of the knee, Osteoarthritis and cartilage 23(12) (2015) 2109-2118.

[6] D. Kalafatovic, E. Giralt, Cell-Penetrating Peptides: Design strategies beyond primary structure and amphipathicity, Molecules 22(11) (2017) 1929.

[7] M. Zorko, Ü. Langel, Cell-penetrating peptides: mechanism and kinetics of cargo delivery, Adv. Drug Delivery Rev. 57(4) (2005) 529-545.

[8] F. Heitz, M.C. Morris, G. Divita, Twenty years of cell- penetrating peptides: from molecular mechanisms to therapeutics, British journal of pharmacology 157(2) (2009) 195-206.

[9] A.D. Frankel, C.O. Pabo, Cellular uptake of the tat protein from human immunodeficiency virus, Cell 55(6) (1988) 1189-1193.

[10] M. Green, P.M. Loewenstein, Autonomous functional domains of chemically synthesized human immunodeficiency virus tat trans-activator protein, Cell 55(6) (1988) 1179-1188.

[11] E. Vives, P. Brodin, B. Lebleu, A truncated HIV-1 Tat protein basic domain rapidly translocates through the plasma membrane and accumulates in the cell nucleus, Journal of Biological Chemistry 272(25) (1997) 16010-16017.

[12] D. Derossi, A.H. Joliot, G. Chassaing, A. Prochiantz, The third helix of the Antennapedia homeodomain translocates through biological membranes, Journal of Biological Chemistry 269(14) (1994) 10444-10450.

[13] H.O. McCarthy, J. McCaffrey, C.M. McCrudden, A. Zholobenko, A.A. Ali, J.W. McBride, A.S. Massey, S. Pentlavalli, K.-H. Chen, G. Cole, Development and characterization of self-assembling nanoparticles using a bio-inspired amphipathic peptide for gene delivery, J. Controlled Release 189 (2014) 141-149.

[14] J.B. Rothbard, S. Garlington, Q. Lin, T. Kirschberg, E. Kreider, P.L. McGrane, P.A. Wender, P.A. Khavari, Conjugation of arginine oligomers to cyclosporin A facilitates topical delivery and inhibition of inflammation, Nat. Med. 6(11) (2000) 1253.

[15] N. Schmidt, A. Mishra, G.H. Lai, G.C. Wong, Arginine- rich cell- penetrating peptides, FEBS letters 584(9) (2010) 1806-1813.

[16] D.J. Mitchell, L. Steinman, D. Kim, C. Fathman, J. Rothbard, Polyarginine enters cells more efficiently than other polycationic homopolymers, The Journal of Peptide Research 56(5) (2000) 318-325.

[17] P.A. Wender, D.J. Mitchell, K. Pattabiraman, E.T. Pelkey, L. Steinman, J.B. Rothbard, The design, synthesis, and evaluation of molecules that enable or enhance cellular uptake: peptoid molecular transporters, Proceedings of the National Academy of Sciences 97(24) (2000) 1300313008. 
[18] S. Futaki, T. Suzuki, W. Ohashi, T. Yagami, S. Tanaka, K. Ueda, Y. Sugiura, Arginine-rich peptides An abundant source of membrane-permeable peptides having potential as carriers for intracellular protein delivery, Journal of Biological Chemistry 276(8) (2001) 5836-5840.

[19] C.-Y. Jiao, D. Delaroche, F. Burlina, I.D. Alves, G. Chassaing, S. Sagan, Translocation and endocytosis for cell-penetrating peptides (CPP) internalization, Journal of Biological Chemistry (2009) jbc. M109. 056309.

[20] J.E. Dixon, G. Osman, G.E. Morris, H. Markides, M. Rotherham, Z. Bayoussef, A.J. El Haj, C. Denning, K.M. Shakesheff, Highly efficient delivery of functional cargoes by the synergistic effect of GAG binding motifs and cell-penetrating peptides, Proceedings of the National Academy of Sciences 113(3) (2016) E291-E299.

[21] L. Thiagarajan, H.A.D.M. Abu- Awwad, J.E. Dixon, Osteogenic programming of human mesenchymal stem cells with highly efficient intracellular delivery of RUNX2, Stem cells translational medicine 6(12) (2017) 2146-2159.

[22] H.M. Eltaher, J. Yang, K.M. Shakesheff, J.E. Dixon, Highly efficient intracellular transduction in three-dimensional gradients for programming cell fate, Acta Biomater. 41 (2016) 181-192. [23] G. Osman, J. Rodriguez, S.Y. Chan, J. Chisholm, G. Duncan, N. Kim, A.L. Tatler, K.M. Shakesheff, J. Hanes, J.S. Suk, PEGylated enhanced cell penetrating peptide nanoparticles for lung gene therapy, J. Controlled Release 285 (2018) 35-45.

[24] G. Puras, J. Zarate, M. Aceves, A. Murua, A. Díaz, M. Avilés-Triguero, E. Fernandez, J. Pedraz, Low molecular weight oligochitosans for non-viral retinal gene therapy, European Journal of Pharmaceutics and Biopharmaceutics 83(2) (2013) 131-140.

[25] J. Fernandez- Carneado, M. Kogan, N. Van Mau, S. Pujals, C. Lopez- Iglesias, F. Heitz, E. Giralt, Fatty acyl moieties: improving Pro- rich peptide uptake inside HeLa cells, The Journal of peptide research 65(6) (2005) 580-590.

[26] J. Regberg, A. Srimanee, Ü. Langel, Applications of cell-penetrating peptides for tumor targeting and future cancer therapies, Pharmaceuticals 5(9) (2012) 991-1007.

[27] J. Fang, Y.-Y. Zhu, E. Smiley, J. Bonadio, J.P. Rouleau, S.A. Goldstein, L.K. McCauley, B.L. Davidson, B.J. Roessler, Stimulation of new bone formation by direct transfer of osteogenic plasmid genes, Proceedings of the National Academy of Sciences 93(12) (1996) 5753-5758. [28] E.G. Tierney, G.P. Duffy, A.J. Hibbitts, S.-A. Cryan, F.J. O'Brien, The development of non-viral gene-activated matrices for bone regeneration using polyethyleneimine (PEI) and collagenbased scaffolds, J. Controlled Release 158(2) (2012) 304-311.

[29] C.M. Curtin, G.M. Cunniffe, F.G. Lyons, K. Bessho, G.R. Dickson, G.P. Duffy, F.J. O'Brien, Innovative Collagen Nano-Hydroxyapatite Scaffolds Offer a Highly Efficient Non-Viral Gene Delivery Platform for Stem Cell-Mediated Bone Formation, Adv. Mater. 24(6) (2012) 749-754. [30] R.M. Raftery, E.G. Tierney, C.M. Curtin, S.-A. Cryan, F.J. O’Brien, Development of a GeneActivated Scaffold Platform for Tissue Engineering Applications Using Chitosan-pDNA Nanoparticles on Collagen-Based Scaffolds, J. Controlled Release 210 (2015) 84-94. [31] R.M. Raftery, D.P. Walsh, I.M. Castaño, A. Heise, G.P. Duffy, S.-A. Cryan, F.J. O'Brien, Delivering Nucleic-Acid Based Nanomedicines on Biomaterial Scaffolds for Orthopedic Tissue Repair: Challenges, Progress and Future Perspectives, Adv. Mater. 28 (2016) 5447-5469. [32] R.M. Raftery, I.M. Castaño, G. Chen, B. Cavanagh, B. Quinn, C.M. Curtin, S.A. Cryan, F.J. O'Brien, Translating the role of osteogenic-angiogenic coupling in bone formation: Highly efficient chitosan-pDNA activated scaffolds can accelerate bone regeneration in critical-sized bone defects, Biomaterials 149 (2017) 116-127.

[33] R.M. Raftery, I. Mencía-Castaño, S. Sperger, G. Chen, B. Cavanagh, G.A. Feichtinger, H. Redl, A. Hacobian, F.J. O'Brien, Delivery of the improved BMP-2-Advanced plasmid DNA within a gene- 
activated scaffold accelerates mesenchymal stem cell osteogenesis and critical size defect repair, J. Controlled Release 283 (2018) 20-31.

[34] I.M. Castaño, C.M. Curtin, G. Shaw, J. Mary Murphy, G.P. Duffy, F.J. O'Brien, A novel collagen-nanohydroxyapatite microRNA-activated scaffold for tissue engineering applications capable of efficient delivery of both miR-mimics and antagomiRs to human mesenchymal stem cells, J. Controlled Release 200(0) (2015) 42-51.

[35] I. Mencía Castaño, C.M. Curtin, G.P. Duffy, F.J. O’Brien, Next generation bone tissue engineering: non-viral miR-133a inhibition using collagen-nanohydroxyapatite scaffolds rapidly enhances osteogenesis, Scientific Reports 6 (2016) 27941.

[36] D.P. Walsh, A. Heise, F.J. O'Brien, S.A. Cryan, An efficient, non-viral dendritic vector for gene delivery in tissue engineering, Gene Ther. 24 (2017) 681.

[37] D.P. Walsh, R.M. Raftery, I.M. Castaño, R. Murphy, B. Cavanagh, A. Heise, F.J. O'Brien, S.-A. Cryan, Transfection of autologous host cells in vivo using gene activated scaffolds incorporating star-polypeptides, J. Controlled Release (2019).

[38] S. Barreto, A. Gonzalez-Vazquez, A.R. Cameron, B. Cavanagh, D.J. Murray, F.J. O'Brien, Identification of the mechanisms by which age alters the mechanosensitivity of mesenchymal stromal cells on substrates of differing stiffness: Implications for osteogenesis and angiogenesis, Acta Biomater. 53 (2017) 59-69.

[39] W.C. Claycomb, N.A. Lanson, B.S. Stallworth, D.B. Egeland, J.B. Delcarpio, A. Bahinski, N.J. Izzo, HL-1 cells: A cardiac muscle cell line that contracts and retains phenotypic characteristics of the adult cardiomyocyte, Proceedings of the National Academy of Sciences 95(6) (1998) 29792984.

[40] F.J. O'Brien, B. Harley, I.V. Yannas, L.J. Gibson, The effect of pore size on cell adhesion in collagen-GAG scaffolds, Biomaterials 26(4) (2005) 433-441.

[41] A. Matsiko, T.J. Levingstone, F.J. O’Brien, J.P. Gleeson, Addition of hyaluronic acid improves cellular infiltration and promotes early-stage chondrogenesis in a collagen-based scaffold for cartilage tissue engineering, J. Mech. Behav. Biomed. Mater. 11 (2012) 41-52.

[42] J. Gleeson, N. Plunkett, F. O'Brien, Addition of hydroxyapatite improves stiffness, interconnectivity and osteogenic potential of a highly porous collagen-based scaffold for bone tissue regeneration, Eur. Cell Mater. 20 (2010) 218-230.

[43] F.J. O'Brien, B.A. Harley, I.V. Yannas, L. Gibson, Influence of freezing rate on pore structure in freeze-dried collagen-GAG scaffolds, Biomaterials 25(6) (2004) 1077-1086.

[44] M.G. Haugh, M.J. Jaasma, F.J. O'Brien, The effect of dehydrothermal treatment on the mechanical and structural properties of collagen- GAG scaffolds, Journal of Biomedical Materials Research Part A 89(2) (2009) 363-369.

[45] S. Prabha, W.-Z. Zhou, J. Panyam, V. Labhasetwar, Size-dependency of nanoparticlemediated gene transfection: studies with fractionated nanoparticles, Int. J. Pharm. 244(1-2) (2002) 105-115.

[46] J. Rejman, V. Oberle, I. Zuhorn, D. Hoekstra, Size-dependent internalization of particles via the pathways of clathrin-and caveolae-mediated endocytosis, Biochem. J 377 (2004) 159-169. [47] W. Jiang, B.Y. Kim, J.T. Rutka, W.C. Chan, Nanoparticle-mediated cellular response is sizedependent, Nature nanotechnology 3(3) (2008) 145.

[48] T. Lehto, K. Ezzat, M.J. Wood, S.E. Andaloussi, Peptides for nucleic acid delivery, Adv. Drug Delivery Rev. 106 (2016) 172-182.

[49] E.T. Jordan, M. Collins, J. Terefe, L. Ugozzoli, T. Rubio, Optimizing electroporation conditions in primary and other difficult-to-transfect cells, Journal of biomolecular techniques: JBT 19(5) (2008) 328. 
[50] Y. Wang, S. Shang, C. Li, Comparison of different kinds of nonviral vectors for gene delivery to human periodontal ligament stem cells, Journal of Dental Sciences 10(4) (2015) 414-422.

[51] J.K. Raty, H.P. Lesch, T. Wirth, S. Yla-Herttuala, Improving safety of gene therapy, Current drug safety 3(1) (2008) 46-53.

[52] K. Corsi, F. Chellat, L.H. Yahia, J.C. Fernandes, Mesenchymal stem cells, MG63 and HEK293 transfection using chitosan-DNA nanoparticles, Biomaterials 24(7) (2003) 1255-1264.

[53] J. Park, R. Lutz, E. Felszeghy, J. Wiltfang, E. Nkenke, F.W. Neukam, K.A. Schlegel, The effect on bone regeneration of a liposomal vector to deliver BMP-2 gene to bone grafts in peri-implant bone defects, Biomaterials 28(17) (2007) 2772-2782.

[54] P. Locatelli, F.D. Olea, A. Hnatiuk, D. Sepúlveda, J.M. Pérez Sáez, R. Argüello, A. Crottogini, Efficient plasmid-mediated gene transfection of ovine bone marrow mesenchymal stromal cells, Cytotherapy 15(2) (2013) 163-170.

[55] W. Wang, W. Li, L. Ou, E. Flick, P. Mark, C. Nesselmann, C.A. Lux, H.H. Gatzen, A. Kaminski, A. Liebold, Polyethylenimine-mediated gene delivery into human bone marrow mesenchymal stem cells from patients, Journal of cellular and molecular medicine 15(9) (2011) 1989-1998. [56] E. Malakooty Poor, M. Baghaban Eslaminejad, N. Gheibi, F. Bagheri, F. Atyabi, ChitosanpDNA nanoparticle characteristics determine the transfection efficacy of gene delivery to human mesenchymal stem cells, Artif. Cells, Nanomed., Biotechnol. 1(1) (2013) 1-9.

[57] C. Jeong, J. Yoo, D. Lee, Y.-C. Kim, A branched TAT cell-penetrating peptide as a novel delivery carrier for the efficient gene transfection, Biomaterials research 20(1) (2016) 28. [58] T. Gonzalez-Fernandez, B.N. Sathy, C. Hobbs, G.M. Cunniffe, H.O. McCarthy, N.J. Dunne, V. Nicolosi, F.J. O'Brien, D.J. Kelly, Mesenchymal stem cell fate following non-viral gene transfection strongly depends on the choice of delivery vector, Acta Biomater. 55 (2017) 226238.

[59] D.P. Walsh, R.D. Murphy, A. Panarella, R.M. Raftery, B. Cavanagh, J.C. Simpson, F.J. O'Brien, A. Heise, S.-A. Cryan, Bioinspired Star-Shaped Poly(I-lysine) Polypeptides: Efficient Polymeric Nanocarriers for the Delivery of DNA to Mesenchymal Stem Cells, Molecular Pharmaceutics 15(5) (2018) 1878-1891.

[60] J.M. Greene, J.M. Feugang, K.E. Pfeiffer, J.V. Stokes, S.D. Bowers, P.L. Ryan, L-arginine enhances cell proliferation and reduces apoptosis in human endometrial RL95-2 cells, Reproductive Biology and Endocrinology 11(1) (2013) 15.

[61] R. Geiger, J.C. Rieckmann, T. Wolf, C. Basso, Y. Feng, T. Fuhrer, M. Kogadeeva, P. Picotti, F. Meissner, M. Mann, L-arginine modulates T cell metabolism and enhances survival and antitumor activity, Cell 167(3) (2016) 829-842. e13.

[62] T. Fujiwara, S. Kanazawa, R. Ichibori, T. Tanigawa, T. Magome, K. Shingaki, S. Miyata, M. Tohyama, K. Hosokawa, L-arginine stimulates fibroblast proliferation through the GPRC6AERK1/2 and PI3K/Akt pathway, Plos one 9(3) (2014) e92168.

[63] M. Mahmoudi, I. Lynch, M.R. Ejtehadi, M.P. Monopoli, F.B. Bombelli, S. Laurent, Proteinnanoparticle interactions: opportunities and challenges, Chem. Rev. 111(9) (2011) 5610-5637. [64] M.P. Monopoli, D. Walczyk, A. Campbell, G. Elia, I. Lynch, F. Baldelli Bombelli, K.A. Dawson, Physical- chemical aspects of protein corona: relevance to in vitro and in vivo biological impacts of nanoparticles, Journal of the American Chemical Society 133(8) (2011) 2525-2534.

[65] F.J. O'Brien, B.A. Harley, I.V. Yannas, L. Gibson, Influence of freezing rate on pore structure in freeze-dried collagen-GAG scaffolds, Biomaterials 25(6) (2004) 1077-1086.

[66] M.G. Haugh, C.M. Murphy, F.J. O'Brien, Novel Freeze-Drying Methods to Produce a Range of Collagen-Glycosaminoglycan Scaffolds with Tailored Mean Pore Sizes, Tissue Eng Part C-Me 16(5) (2010) 887-894. 
[67] C.M. Brougham, T.J. Levingstone, N. Shen, G.M. Cooney, S. Jockenhoevel, T.C. Flanagan, F.J. O'brien, Freeze-Drying as a Novel Biofabrication Method for Achieving a Controlled Microarchitecture within Large, Complex Natural Biomaterial Scaffolds, Adv. Healthcare Mater. 6(21) (2017) 1700598.

[68] C. O'Leary, B. Cavanagh, R.E. Unger, C.J. Kirkpatrick, S. O'Dea, F.J. O'Brien, S.-A. Cryan, The development of a tissue-engineered tracheobronchial epithelial model using a bilayered collagen-hyaluronate scaffold, Biomaterials 85 (2016) 111-127.

[69] A.J. Ryan, F.J. O'Brien, Insoluble elastin reduces collagen scaffold stiffness, improves viscoelastic properties, and induces a contractile phenotype in smooth muscle cells, Biomaterials 73 (2015) 296-307.

[70] E. Farrell, F.J. O'Brien, P. Doyle, J. Fischer, I. Yannas, B.A. Harley, B. O'Connell, P.J. Prendergast, V.A. Campbell, A collagen-glycosaminoglycan scaffold supports adult rat mesenchymal stem cell differentiation along osteogenic and chondrogenic routes, Tissue Eng. 12(3) (2006) 459-468.

[71] I. Yannas, E. Lee, D. Orgill, E. Skrabut, G. Murphy, Synthesis and characterization of a model extracellular matrix that induces partial regeneration of adult mammalian skin, Proceedings of the National Academy of Sciences 86(3) (1989) 933-937.

[72] C.M. Brougham, T.J. Levingstone, S. Jockenhoevel, T.C. Flanagan, F.J. O'Brien, Incorporation of fibrin into a collagen-glycosaminoglycan matrix results in a scaffold with improved mechanical properties and enhanced capacity to resist cell-mediated contraction, Acta Biomater. 26 (2015) 205-214.

[73] A. Matsiko, T.J. Levingstone, J.P. Gleeson, F.J. O'Brien, Incorporation of TGF-Beta 3 within Collagen-Hyaluronic Acid Scaffolds Improves their Chondrogenic Potential, Adv. Healthcare Mater. 4(8) (2015) 1175-1179.

[74] T.J. Levingstone, E. Thompson, A. Matsiko, A. Schepens, J.P. Gleeson, F.J. O’Brien, Multilayered collagen-based scaffolds for osteochondral defect repair in rabbits, Acta Biomater. 32 (2016) 149-160.

[75] W.A. Lackington, R.M. Raftery, F.J. O'Brien, In vitro efficacy of a gene-activated nerve guidance conduit incorporating non-viral PEI-pDNA nanoparticles carrying genes encoding for NGF, GDNF and c-Jun, Acta Biomater. (2018).

[76] J.P. Gleeson, T.J. Levingstone, F.J. O'brien, Layered scaffold suitable for osteochondral repair, Google Patents, 2010.

[77] F. David, T.J. Levingstone, W. Schneeweiss, M. Swarte, H. Jahns, J.P. Gleeson, F.J. O'Brien, Enhanced bone healing using collagen-hydroxyapatite scaffold implantation in the treatment of a large multiloculated mandibular aneurysmal bone cyst in a thoroughbred filly, Journal of tissue engineering and regenerative medicine 9 (10) (2015) 1193-9.

[78] F.G. Lyons, J.P. Gleeson, S. Partap, K. Coghlan, F.J. O’Brien, Novel Microhydroxyapatite Particles in a Collagen Scaffold: A Bioactive Bone Void Filler?, Clinical orthopaedics and related research 472(4) (2014) 1318-1328.

[79] M. Alhag, E. Farrell, M. Toner, N. Claffey, T.C. Lee, F. O'Brien, Evaluation of early healing events around mesenchymal stem cell-seeded collagen-glycosaminoglycan scaffold. An experimental study in Wistar rats, Oral Maxillofac Surg 15(1) (2011) 31-39.

[80] F.G. Lyons, A.A. Al-Munajjed, S.M. Kieran, M.E. Toner, C.M. Murphy, G.P. Duffy, F.J. O'Brien, The healing of bony defects by cell-free collagen-based scaffolds compared to stem cell-seeded tissue engineered constructs, Biomaterials 31(35) (2010) 9232-9243.

[81] A. Wilber, J.L. Frandsen, K.J. Wangensteen, S.C. Ekker, X. Wang, R.S. Mclvor, Dynamic gene expression after systemic delivery of plasmid DNA as determined by in vivo bioluminescence imaging, Human gene therapy 16(11) (2005) 1325-1332. 
[82] T. Jiang, E.S. Olson, Q.T. Nguyen, M. Roy, P.A. Jennings, R.Y. Tsien, Tumor imaging by means of proteolytic activation of cell-penetrating peptides, Proceedings of the National Academy of Sciences 101(51) (2004) 17867-17872.

[83] E.G. Tierney, K. McSorley, C.L. Hastings, S.-A. Cryan, T. O'Brien, M.J. Murphy, F.P. Barry, F.J. O'Brien, G.P. Duffy, High levels of ephrinB2 over-expression increases the osteogenic differentiation of human mesenchymal stem cells and promotes enhanced cell mediated mineralisation in a polyethyleneimine-ephrinB2 gene-activated matrix, J. Controlled Release 165(3) (2013) 173-182.

[84] S. Yamano, J. Dai, A.M. Moursi, Comparison of transfection efficiency of nonviral gene transfer reagents, Mol. Biotechnol. 46(3) (2010) 287-300.

[85] H. Madry, S. Trippel, Efficient lipid-mediated gene transfer to articular chondrocytes, Gene Ther. 7(4) (2000) 286.

[86] J. Haag, R. Voigt, S. Soeder, T. Aigner, Efficient non-viral transfection of primary human adult chondrocytes in a high-throughput format, Osteoarthritis and cartilage 17(6) (2009) 813817.

[87] S. Dickens, S. Van den Berge, B. Hendrickx, K. Verdonck, A. Luttun, J.J. Vranckx, Nonviral transfection strategies for keratinocytes, fibroblasts, and endothelial progenitor cells for ex vivo gene transfer to skin wounds, Tissue Engineering Part C: Methods 16(6) (2010) 1601-1608.

[88] N. Nguyen, M. Biet, É. Simard, É. Béliveau, N. Francoeur, G. Guillemette, R. Dumaine, M. Grandbois, G. Boulay, STIM1 participates in the contractile rhythmicity of HL-1 cells by moderating T-type Ca2+ channel activity, Biochimica et Biophysica Acta (BBA) - Molecular Cell Research 1833(6) (2013) 1294-1303.

[89] I. Bozo, R. Deev, A. Drobyshev, A. Isaev, I. Eremin, World's first clinical case of geneactivated bone substitute application, Case reports in dentistry 2016 (2016).

[90] C.M. Curtin, E.G. Tierney, K. McSorley, S.-A. Cryan, G.P. Duffy, F.J. O'Brien, Combinatorial Gene Therapy Accelerates Bone Regeneration: Non-Viral Dual Delivery of VEGF and BMP2 in a Collagen-Nanohydroxyapatite Scaffold, Adv. Healthcare Mater. 4(2) (2015) 223-227.

[91] H. Peng, V. Wright, A. Usas, B. Gearhart, H.-C. Shen, J. Cummins, J. Huard, Synergistic enhancement of bone formation and healing by stem cell-expressed VEGF and bone morphogenetic protein-4, Journal of Clinical Investigation 110(6) (2002) 751-759.

[92] W.F. McKay, S.M. Peckham, J.M. Badura, A comprehensive clinical review of recombinant human bone morphogenetic protein-2 (INFUSE ${ }^{\circledR}$ Bone Graft), Int. Ortho. 31(6) (2007) 729-734. [93] C.S. Bahney, D.P. Hu, T. Miclau III, R.S. Marcucio, The multifaceted role of the vasculature in endochondral fracture repair, Frontiers in endocrinology 6 (2015) 4.

[94] D.P. Hu, F. Ferro, F. Yang, A.J. Taylor, W. Chang, T. Miclau, R.S. Marcucio, C.S. Bahney, Cartilage to bone transformation during fracture healing is coordinated by the invading vasculature and induction of the core pluripotency genes, Development 144(2) (2017) 221-234. [95] H. Peng, A. Usas, A. Olshanski, A.M. Ho, B. Gearhart, G.M. Cooper, J. Huard, VEGF improves, whereas sFlt1 inhibits, BMP2-induced bone formation and bone healing through modulation of angiogenesis, Journal of Bone and Mineral Research 20(11) (2005) 2017-2027.

[96] P.P. Spicer, J.D. Kretlow, S. Young, J.A. Jansen, F.K. Kasper, A.G. Mikos, Evaluation of bone regeneration using the rat critical size calvarial defect, Nature protocols 7(10) (2012) 1918-1929. [97] E. Quinlan, E.M. Thompson, A. Matsiko, F.J. O'brien, A. López-Noriega, Functionalization of a collagen-hydroxyapatite scaffold with osteostatin to facilitate enhanced bone regeneration, Adv. Healthcare Mater. 4(17) (2015) 2649-2656.

[98] E. Quinlan, E.M. Thompson, A. Matsiko, F.J. O'Brien, A. López-Noriega, Long-term controlled delivery of rhBMP-2 from collagen-hydroxyapatite scaffolds for superior bone tissue regeneration, J. Controlled Release 207(0) (2015) 112-119. 
[99] B. Li, H. Wang, G. Qiu, X. Su, Z. Wu, Synergistic Effects of Vascular Endothelial Growth Factor on Bone Morphogenetic Proteins Induced Bone Formation In Vivo: Influencing Factors and Future Research Directions, BioMed Research International 2016 (2016). 